11 Núria M. Pinyol

12

13

14

15

16

17

18

19

20

21

22

23

24

25

26

27

28

29

30
Mauricio Alvarado

Núria M. Pinyol

Eduardo E. Alonso

Eduardo E. Alonso

(1)

\title{
Landslide motion assessment including rate effects and thermal interactions. Revisiting Canelles landslide.
}

PhD Researcher

Centre Internacional de Metodes Numerics en Enginyeria

Barcelona, Spain

PhD. Associate research professor

Centre Internacional de Metodes Numerics en Enginyeria

Division of Civil and Environmental Engineering

Universitat Politècnica de Catalunya, Barcelona, Spain

PhD. Full professor

Department of Civil and Environmental Engineering

Universitat Politècnica de Catalunya, Barcelona, Spain 


\section{Landslide motion assessment including rate effects and thermal interactions. Revisiting Canelles landslide.}

\section{ABSTRACT}

The reactivation of a large $\left(40 \mathrm{Mm}^{3}\right)$ landslide on the valley slopes of a reservoir motivated a research initiative to estimate the risk of a fast sliding mass moving into the reservoir. Previous simplified analysis had suggested that a joint consideration of strain rate effects on friction and thermal pressurization phenomena in the sliding surface could provide a rational approach to answer the question raised. The paper describes first the capability of strain rate effects on friction to reproduce long-term creeping records of two real cases. The joint and coupled phenomena of creeping motion and thermal pressurization in shearing bands was incorporated into a material point method computational technique for hydro-mechanical analysis of porous materials. A representative cross section of Canelles landslide was then analysed, profiting from previous finite element investigation of the landslide. It was found that the rate of a rapid landslide acceleration could be a possibility under extreme external actions. However, it was also found that a moderate strain rate effect on basal residual friction angle was capable of avoiding the triggering of a fast motion.

Keywords: landslides, strain rate effects, thermal interaction, frictional work, large displacements, material point method, real case.

\section{INTRODUCTION}

When dealing with natural or man excavated slopes, a relevant issue refers to the consequences of a potential instability. Risk assessment depends on the post failure behaviour in terms of run-out and velocity. Once the instability is triggered field observations indicate that landslides may exhibit widely different velocities ranging from 
57 extremely slow (velocities lower than $16 \mathrm{~mm} /$ year) to extremely rapid (velocities higher 58 than $5 \mathrm{~m} / \mathrm{sec}$ ) (International Union of Geological Sciences/International Working Group on 59 Landslides 1995).

Several factors determine the evolution of the motion, i.e. external actions, kinematic restrictions, motion dynamics and the constitutive response of the involved materials. The latter depends on the intensity of straining but also on thermal interactions due to frictional work dissipation along the sliding surface. This is a complex and challenging problem, which involves large deformations and large displacements. The difficulties of performing quantitative analyses explains that landslide risk is often assessed with empirical tools and procedures relying on field observations, empirical relationships, statistical methodologies and mapping techniques.

This paper is a contribution to improve the current understanding of post-failure sliding mechanisms and their modelling.

Under the assumption of planar landslide and a simple frictional Mohr-Coulomb law, the application of second Newton law shows that a slight reduction of safety factor below one leads to a high sliding velocity in a few seconds even in cases of small slope inclinations. The safety factor is here defined as the ratio between the available and the mobilized shear strength. However, field observations indicate that active landslides (whose notional classical safety factor is equal to or lower than one) remain in the range of slow velocities. This is the case of two active landslides analysed in the first part of this paper.

With the aim of providing an explanation of the creeping motion observed in well documented active landslides, in contrast to the accelerated motion predicted by simple frictional laws, some modelling approaches introduced the effect of the shearing velocity (or shear strain rate) on the resistance forces. This approach explains that landslides will 
reach a constant velocity after the initiation of the movement, even if the intensity of the triggering factor is maintained.

Two different approaches can be found in the literature to address the increase of the resistance forces with the motion. On the one hand, the dynamic behaviour is represented by adding a viscous component to the terms describing resistance forces in the momentum balance equations. A common procedure is to accept that the soil develops a viscous resistance force, proportional to the shearing rate, once the shear stresses on the sliding surface exceed a threshold (Bingham model). In particular, Angeli et al. (1996) and Corominas et al. (2005) analyse the response of two landslides, also discussed in this paper, including this viscous strength component.

A second approach is followed by Bowden \& Tabor (1964), Mitchell (1976), Rice \& Ruina (1983), Davis et al. (1993) and Wedage et al. (1998b). The effect of the sliding velocity is incorporated into the expression of the friction angle and, therefore, the velocitydependent contribution on the strength is automatically affected by the applied normal stress. In these approaches, a logarithmic or exponential increment of friction with the strain rate is proposed to define the variation of the residual strength from a low value of the friction angle $\left(\phi_{\min }\right)$, associated with the residual value for very slow velocities, to a maximum value $\left(\phi_{\max }\right)$, sometimes defined as an asymptotic value, associated with large shearing velocities.

Other alternatives to predict the landslide behaviour are based on phenomenological laws relating directly the slope velocities to the rainfall historical record or to the local safety factor computed on the sliding surface (i.e. Vulliet and Hutter, 1988; Cascini et al., 2010).

Rate effects on frictional strength have been examined in the laboratory by Skempton (1985), Dieterich (1979), Ruina (1983), Tika \& Hutchinson (1999), Di Toro et al. (2006), Liao et al. (2011), Yang et al. (2014) and Wedage et al. (1998a). Alonso et al. (2016) review 
106

published experimental observations and offer a discussion from a theoretical point of view of the strain rate dependence of friction angle.

In this paper, rate effects are also invoked to explain the behaviour observed in the large Canelles landslide. As described in Pinyol et al. (2012) and Pinyol et al. (2016), a large unstable mass was identified in a valley slope of one of the largest reservoirs in Spain (the largest one in Catalonia). In 2006, after a rapid drawdown of the reservoir water level, the landslide was reactivated. The landslide boundary was identified by a two kilometre long continuous deep crack, marking the position of the landslide crest. A field survey of the crack opening indicated that the initial landslide displacement ranged between 0.1 and 0.3 m (Figure 1). Geological and geotechnical investigation carried out later led to identify a $40 \times 10^{6} \mathrm{~m}^{3}$ mobilized mass.

The instability and the risk of a sudden acceleration of the landslide entering into the reservoir at high speed alarmed the reservoir owners and state authorities. The resulting study of the case was presented in Pinyol et al. (2012). The analysis carried out focused on inquiring the causes of the failure and on establishing mitigation measures and/or protocols of reservoir management guaranteeing the stability of landslide and, in particular, the prevention of an uncontrolled landslide failure leading to an invasion of the reservoir at high velocity.

Pinyol et al. (2012) describe a hydro-mechanical coupled analysis of the landslide with the purpose of investigating the pore water pressure distribution in the valley slope, significantly affected by the changing levels of reservoir elevation as well as by rainfall. The numerical results were validated by pore pressure registered by vibrating wire piezometers installed in deep boreholes after the sliding reactivation. A limit equilibrium analysis indicated that the failure was induced by a strong drawdown, which occurred in the summer of 2006, following a previous long period ( 4 yrs) of high and relatively constant water level in the reservoir. 
132 In the analysis reported by Pinyol et al. (2012), the potential risk of fast sliding was evaluated 133 by considering the development of thermally-induced loss of frictional strength at the basal 134 shear surface. This phenomenon has been widely invoked by many authors to explain rapid 135 landslides, more specifically the case of Vaiont landslide (Habib 1975; Uriel Romero \& 136 Molina 1977; Voight \& Faust 1982; Vardoulakis 2000; Vardoulakis 2002; Goren \& Aharonov 137 2007; Goren \& Aharonov 2009; Veveakis et al. 2007; Pinyol \& Alonso 2010a; Pinyol \& Alonso 138 2010b; Cecinato et al. 2011). A summary of contributions to thermal analysis of catastrophic 139 landslides is presented by Alonso et al. (2016).

140 The coupled thermo-hydro-mechanical analysis of Canelles landslide was carried out 141 following the approach presented in Pinyol \& Alonso (2010a). A representative cross142 section was analysed by means of two interacting blocks, whose size (mass) evolves during 143 the motion. The frictional work dissipated in heat was exclusively developed along the 144 sliding basal surface defined "a priori", located at the lower boundary of the pre-defined 145 rigid blocks. This analysis, which accounted for the known material properties and the pore 146 water pressure distribution induced by the rapid drawdown of the reservoir level, led to 147 two conclusions:

148 a) The mobilized mass exhibited a potential risk to accelerate and

149 b) It could impact the reservoir at a high velocity $(16 \mathrm{~m} / \mathrm{s})$ a few seconds after the initiation 150 of the motion.

151 However, the slide did not accelerate as a consequence of the initial reactivation, following 152 the rapid reservoir level drawdown. The creeping motion of the slide actually observed and 153 its subsequent stabilization after less than $0.5 \mathrm{~m}$ of overall displacement could not be 154 explained by the thermo-hydro-mechanical approach developed. Conceptually, this failure 155 of the model to capture the landslide response after reactivation, does not invalidate the 156 suspicion that, under other circumstances (for instance an unexpectedly high phreatic level 157 increase because of heavy rains) a risk of a strong slide acceleration still exists. In a sense, 158 this cautious attitude is confirmed by the case of Vajont landslide (Italy). In Vajont, an 
159

accumulated displacement, close to $4 \mathrm{~m}$, during three years of creeping motions, was registered prior to the catastrophic event in 1963 (Hendron \& Patton 1985).

The case of Canelles landslide is revisited in this paper with the purpose of giving a more complete explanation of the observed behaviour, being consistent with the thermal interaction phenomenon. The analysis is carried out by means of the material point method (MPM) (Sulsky \& Schreyer 1996; Bardenhagen et al. 2000) which is selected because of its capabilities to reproduce the entire response of landslides, including static conditions, landslide triggering and post failure behaviour (Bandara et al. 2016; Ceccato 2017; Ceccato \& Simonini 2016; Soga et al. 2016; Yerro et al. 2015a; Yerro et al. 2015b; Zabala \& Alonso 2011).

A MPM code for two-phase deformable porous materials was recently extended to solve non-isothermal problems and to address thermal interactions in landslide mobility (Pinyol et al. 2018). Rate effects on friction were also added to the computational tool. The performance of the new modelling approach is reported in this paper in connection with Canelles landslide.

\section{Rate effects on creeping landslides}

Consider two real landslides described in the literature:

- Alverà slide in Veneto, Italy (Panizza et al. 1996; Angeli et al. 1996).

- Vallcebre landslide in Pyrenees, Spain (Corominas et al. 2005).

Both of them are active landslides that were monitored during a long period of time. Representative landslide geometry and the position of the sliding surface and the main features of the involved materials are available. In addition, in the two cases, the registered motion can be well correlated with the water level evolution and the accumulated displacement during a relatively long period. Figure 2 and Figure 3 show representative cross sections of the slides. The geometry of the slides was simplified as a planar landslide adopting the average thickness and average angle of inclination. Table 1 summarizes the relevant data. 
where

$$
\tan \phi_{v_{\text {const }}}=\tan \beta /\left(1-\frac{\gamma_{w} h_{w}}{\gamma_{s} D}\right)
$$

207 This law (Eq. 6) was used to simulate the behaviour of the two real cases referred above 208 (Table 1). The evolution of the water levels of each case has been introduced according to 209

For the analysis of these cases, the following frictional law for the residual strength is defined in terms of the sliding velocity, $v$ :

$$
\tan \phi_{v}=\tan \phi_{\min }+\left(\tan \phi_{\max }-\tan \phi_{\min }\right)\left(1-\mathrm{e}^{-\chi v}\right)
$$

where the friction angle is controlled with the parameter $\chi$. The sub-index $v$ indicates the dependence of the friction angle with the velocity.

For planar slides, defined by the sliding surface at a depth $D$, inclination $\beta$ and a level of water parallel to the sliding surface at a height with respect to the sliding surface $h_{w}$, Newton's second law leads to the following differential equation defining the acceleration of the slide ( $a=\frac{\mathrm{d} v}{\mathrm{~d} t}$, where $\frac{\mathrm{d} v}{\mathrm{~d} t}$ is the time derivative of the velocity):

$$
\frac{\mathrm{d} v}{\mathrm{~d} t}=g\left[\tan \beta-\left(1-\frac{\gamma_{w} h_{w}}{\gamma_{s} D}\right) \tan \phi_{v}\right]
$$

In Equation (2), $\gamma_{w}$ and $\gamma_{s}$ are the specific weights of water and $g$ the gravity acceleration. For a given frictional law (Eq. (1)), a range a minimum $\left(h_{w_{-} \min }\right)$ and maximum value $\left(h_{w_{-} \max }\right)$ of water level can be established:

$$
\begin{aligned}
& h_{w_{-} \text {min }}=\frac{\gamma_{s} D}{\gamma_{w}}\left(1-\frac{\tan \beta}{\tan \phi_{\min }}\right) \\
& h_{w_{-} \max }=\frac{\gamma_{s} D}{\gamma_{w}}\left(1-\frac{\tan \beta}{\tan \phi_{\max }}\right)
\end{aligned}
$$


modelling the two cases corresponds to the residual angle measured in ring shear tests and reported in the reference papers.

212 There is no available experimental data regarding the variation of the friction angle with the 213 velocity in the two analysed landslides. Wang et al. (2010), based on experimental data on 214 two soils, a clayey and a silty soil of low to medium plasticity, reported large increments of 215 friction angle up to $18^{\circ}$ associated with increments of velocity between 0.001 to $100 \mathrm{~mm} / \mathrm{s}$. 216 Wedage et al. (1998a) collected experimental data showing strain rate effects on the 217 residual friction of clays. For high plasticity clay shales they found friction increments of 3\% $218-3.5 \%$ per log cycle of strain rate.

219 In the cases analysed here, the maximum values of friction angles and the values of the 220 parameter controlling the strength increase variation, $\chi$, were determined with the 221 condition of fitting the measured accumulated displacement. The selected values are given 222 in Table 1. The friction angle evolution with respect to the velocity, for each case, is plotted 223 in Figure 6.

224 Figure 4 and Figure 5 compare the evolution of the landslide velocity and acceleration 225 calculated and measured for the two cases analysed. The agreement is reasonably good. 226 The peak acceleration measured in January 1991 in Alverà slide is poorly reproduced by the 227 model. The computational model is able to interpret the evolution of the landslide motion 228 induced by changes in external action and the resistant forces. The velocity increment 229 registered in 01/91 cannot be correlated with an increase of the water level (notice that the 230 water level at this period did not increase significantly compared with the rest of values) 231 and the velocity reached a maximum of $12 \mathrm{~m} /$ day. This circumstance cannot be reproduced 232 by the computational model.

233 It can be concluded that a simple law for rate effect on residual friction is able to explain 234 the observed response of active creeping landslides subjected to the recorded water level 235 changes. Observed discrepancies between measurements and model results can be a 236 consequence of the simplified geometry assumed. However, the question of the expected 237 evolution of these landslide against a more intense increase in pore water pressure, is not 
properly addressed in the model outlined and, in particular, the possibility of a sudden acceleration is not contemplated in $\mathrm{Eq}(2)$.

\section{Revisiting Canelles Landslide}

The geological and geotechnical study carried out on Canelles landslide led to identify the mechanism of the motion, its internal geometry and the magnitude of the mobilized mass. The instability observed in Canelles landslide in 2006 was analysed by Pinyol et al. (2012) by means of two dimensional finite element analysis of the representative section shown in Figure 7. The position of the sliding surface was located in a continuous and relatively thin red claystone unit.

According to Pinyol et al. (2012), Canelles instability was induced by a rapid drawdown of the reservoir that partially submerged the toe of the slope. The excess pore water pressure remaining inside of the slope, after drawdown, was analysed by means of a finite element code (CODE BRIGHT), which is able to deal with coupled hydro-mechanical problems under saturated and non-saturated conditions in deformable porous media (Olivella et al. 1996; Code_Bright, 2018). The variation of the reservoir water elevation during the period 2002 to 2010 and the average rainfall registered in the site were simulated.

The results in terms of time variation of pore water pressure were compared with the measured values registered during two years (2008 and 2009) by piezometers installed in the proximity of the estimated position of the sliding failure. The good agreement between measurements and computed results provided reliability to the model. However, the pore water pressure registered in the upper part of the slope was underestimated by the model.

The residual frictional strength at low strain rate of the marl layer was evaluated by a ring shear test on two saturated remoulded samples under effective vertical stress ranging from $100 \mathrm{kPa}$ to $250 \mathrm{kPa}$. The measured effective friction angle ranged between $12^{\circ}$ and $13^{\circ}$. The "in situ" vertical effective stress prevailing at the marl layer (located at depths of 50-100 m) is significantly higher ( $800 \mathrm{kPa}$ in average) than the confining stress values applied to the 
test. Unfortunately, the frictional angle available along the polished sliding surfaces recovered in core samples was not evaluated.

The friction angle obtained by back-analysis in Pinyol et al. (2012) by means of limit equilibrium analysis was slightly smaller than the value obtained in ring shear tests. As discussed in Pinyol et al. (2012), taking into account the non-linearity of the strength with the normal stress, the in situ value of the residual friction angle at the in-situ polished sliding surface is probably smaller than the values reported above for the ring shear tests performed. In addition, if we accept the back-calculated value of the friction angle as a more reliable value, the fact of that it is smaller than the residual value obtained in the laboratory indicates that the sliding surface exhibits residual conditions. However, ring shear tests on clay indicate that a change in shearing rate leads, for a short time, to a peak strength followed by a strain softening to a new residual situation (Tika et al, 1996; Tika and Hutchinson, 1999). Direct shear tests on polished rock surfaces (Dieterich, 1979), show a similar behaviour. Healing mechanisms, after a resting period may lead also to a transient increase in peak strength before dropping to residual conditions. The effect of these phenomena on the reaction of the landslide after reactivation is discussed later on.

Pinyol et al. (2012) concluded that the pore water pressure computed in the summer of 2006 after a strong drawdown could explain the failure detected in the field by a continuous crack and a small 'jump' in some inclinometers along a pre-existing sliding surface at residual conditions located in a low- permeability clayey layer.

This case is revisited in this paper with the aim of analysing the post failure behaviour including the effect of strain rate dependence of frictional strength, thermal interactions and the strain softening implied by the reactivation and a previous resting period. The MPM is used to evaluate the post failure response of the slide because of its capabilities to deal with large displacements in history-dependent materials. The case is modelled with GEOPART code (Zabala et al. 2004; Zabala \& Alonso 2011), a general code which was recently extended to solve non isothermal problems to address thermal interactions in 
292 landslide mobility (Pinyol et al. 2018, Alvarado 2018) and creeping phenomena through rate 293 effects on friction.

294

295

296

297

298

299

300

301

302

303

304

305

306

307

308

309

311

312

313

314

315

$$
\dot{H}=\boldsymbol{\sigma}^{\prime}: \dot{\boldsymbol{\varepsilon}}_{p}
$$

\section{MPM computational model}

The representative two-dimensional cross-section of Canelles landslide shown in Figure 7 (cross-section II reported in Pinyol et al. 2012) was discretised by the computational mesh and material point distribution shown in Figure 8. The computational mesh (a regular Cartesian mesh with element size of $4 \times 2 \mathrm{~m}$ ) defines the computational domain. The initial location of the material points (four material points per element distributed in the position corresponding to integration points of a four-point Gaussian quadrature) describes the initial geometry of the slope before the failure observed in 2006. Following the same approach presented in Pinyol et al. (2012), two materials are distinguished for modelling purposes (Figure 8): the basal clay layer and the mobilized rock located above the clay layer, which mainly consists of siltstone and limestone layers.

\section{Governing equations and constitutive behaviour}

Thermal effects are included in the analysis. Solid and water mass balance equations are solved in a coupled way with the energy balance equations formulated for the mixture (Pinyol et al. 2018). The energy balance equation states that the sum of the following terms:

- the internal energy in solid and liquid phase, which depend on their specific heats ( $c_{L}$ for liquid and $c_{S}$ for solid);

- the conduction of heat flow driven by temperature gradients and governed by Fourier's law which depends on the heat conductivity $(\Gamma)$; and

- the convective heat transport due to liquid and solid flow;

should be equal to the external supply of heat rate, $\dot{H}$, generated by the dissipation in heat of the plastic work:

where $\boldsymbol{\sigma}^{\prime}$ is the Cauchy stress tensor and $\dot{\boldsymbol{\varepsilon}}_{p}$ the plastic strain rate tensor. 
The mass balance equation for the mixture includes the thermal effects on solid and water densities due to the heat generated by the dissipation of the frictional work. This is included in the calculation by means of the following constitutive laws:

$$
\begin{aligned}
& \rho_{S}=\rho_{S}^{0} \exp \left[-\beta_{S}\left(\theta-\theta^{0}\right)\right] \\
& \rho_{L}=\rho_{L}^{0} \exp \left[\alpha_{L}\left(p_{L}-p_{L}^{0}\right)-\beta_{L}\left(\theta-\theta^{0}\right)\right]
\end{aligned}
$$

320 where $\rho_{S}^{0}$ and $\rho_{L}^{0}$ are the solid and liquid density at reference temperature $\theta^{0}\left(2700 \mathrm{~kg} / \mathrm{m}^{3}\right.$, $3211000 \mathrm{~kg} / \mathrm{m}^{3}$ at $20^{\circ}$ ) and liquid pressure $p_{L}^{0}$. The parameter $\alpha_{L}$ defines the liquid phase 322 compressibility and $\beta_{S}$ and $\beta_{L}$ are the volumetric thermal expansion coefficients for solid 323 and liquid phase, respectively. Notice that the liquid density variation induced by changes 324 of the pore water pressure is also included. On the contrary, the compressibility of the solid 325 particles against changes in stress is assumed negligible.

326 Table 2 collects the model parameters for the materials of Canelles landslide. The thermal 327 dilation coefficients, the specific heat of the water and solid particles and the thermal 328 conductivity coefficient $\Gamma$ are taken from accepted reference values. The mechanical 329 parameters defining the elastic compressibility and the peak and residual strength were 330 defined as representative values taking into account the properties of rock banks above the 331 clay layer described in the geological analysis carried out in Pinyol et al. (2012).

332 Materials involved in Canelles landslide were defined by means of a Mohr-Coulomb law. 333 Strain softening and strain rate hardening are included in the generalized Mohr-Coulomb 334 model by means of the following definition of the effective friction angle:

$$
\phi^{\prime}=\phi_{r e s}^{\prime}+\left(\phi_{p e a k}^{\prime}-\phi_{r e s}^{\prime}\right) \mathrm{e}^{-\eta \varepsilon_{d}^{p}}+\bar{\phi}^{\prime}\left(1-\mathrm{e}^{-\alpha \dot{\varepsilon}_{d}^{p}}\right)
$$

335 where, $\phi_{\text {peak }}^{\prime}$ and $\phi_{\text {res }}^{\prime}$ are the maximum and minimum effective friction angle associated 336 with shearing at a slow strain rate, $\eta$ is a model parameter which controls this loss of 337 strength, $\bar{\phi}^{\prime}$ is the maximum increment of the effective friction angle due to rate effects, 338 and $\alpha$ is the parameter controlling the rate strain effects. $\varepsilon_{d}^{p}$ is the deviatoric plastic strain 339 and $\dot{\varepsilon}_{d}^{p}$ is the deviatoric plastic strain rate. 
340 The derivation of the incremental stress-strain relationship including rate effects follows

341 Wedage et al. (1998b). The resulting rate-controlled elastoplastic model was implemented 342 into the MPM code. An explicit integration scheme with substepping algorithm, error 343 control and a correction for the yield surface drift was applied (Sloan et al. 2001).

344 At a first stage of the analysis and according to the previous discussion, the basal clay layer 345 is assumed to be at residual conditions. A sensitivity analysis of strain softening effects is 346 evaluated later. A moderate strain softening characterizes residual conditions. The effect of 347 the strain-rate increase of friction angle applies to the entire strain softening process.

348 Figure 9 shows the gain in friction coefficient for increasing shear strain rate at the sliding 349 surface for different values of the maximum increase in friction angle $\left(\bar{\phi}^{\prime}\right)$ and the 350 coefficient $\alpha$. A moderate maximum increase in residual friction $\left(\bar{\phi}^{\prime}=2^{\circ}\right)$ and a value $\alpha=$ $35110^{7}(1 / \mathrm{s})$ were adopted (Table 2). It is consistent with the correlation between the increase 352 of shear strength and the plasticity index presented by Wedage et al. (1998a) based on tests 353 on clays and clay shales.

354 The strain-softening law (Eq. 10) characterizes the mobilized rock above the sliding surface 355 without including strain rate effects. The estimated peak and residual values are indicated 356 in Table 2. These values were selected taking into account the properties of rock layers 357 described in the geological analysis carried out in Pinyol et al. (2012).

358 Table 2 also indicates the values of permeability. In the MPM analysis presented, water flow 359 plays an important role because it controls the dissipation of the excess pore water pressure 360 induced by thermal interaction. The permeability value considered for the clay layer was 361 determined in the laboratory (Pinyol et al. 2012). The permeability value assigned to the 362 mobilized rock layers above the clay level was estimated by matching the registered 363 evolution of water pressures in the piezometers installed in boreholes at different depths. 364 However, a sensitivity analysis of the effect of these values was carried out. It was 365 concluded that, for values ranging between $10^{-4} \mathrm{~m} / \mathrm{s}$ and $10^{-7} \mathrm{~m} / \mathrm{s}$ for the limestone and 
366 between $10^{-7} \mathrm{~m} / \mathrm{s}$ and $10^{-11} \mathrm{~m} / \mathrm{s}$ for the clay layer, there were no significant effects on the 367 results in terms of the landslide motion.

368 The water filling the reservoir is also modelled. The water material is characterized as elastic 369 body defined by its real volumetric compressibility coefficient (2200 MPa) and imposing a 370 shearing modulus close to zero. This procedure allows the simulation of the water effect on 371 the slope, including the inertial forces of the water during the motion. This dynamic effect 372 of the water motion was not included in Pinyol et al. (2012).

\section{Mesh size effects and embedded shear bands}

374 The non-isothermal hydromechanical problem modelled in this article exhibits a high 375 dependence on the thickness of the shear band (Pinyol et al. 2018). In fact, the rate of heat 376 generated in the sliding surface is proportional to the strain which depends on the thickness 377 of the shear band for a given sliding velocity. Given a relative displacement, the thicker the 378 shear band, the smaller the shear strain and the smaller the heat generated per unit 379 volume, which controls the temperature increments and the heat-induced excess pore 380 water pressure generated.

381 In a continuum approach (i.e. standard FEM or the MPM used in this analysis), the strains 382 tend to localize into a single or a few elements. Therefore, taking into account the 383 dependence of results on the shear band thickness, a proper modelling would require 384 discretizing the domain, where shear bands develop, in elements whose size is able to 385 simulate realistic shear bands (a few millimetres or centimetres thick in case of fine soils). 386 In practice, such discretization in elements of a few millimetres size would involve a high 387 computational cost, which makes it impossible the simulation of large landslides.

388 In order to overcome such limitation, Pinyol et al. (2018) present a novel procedure in which 389 numerical "embedded shear bands" are included to calculate the heat rate generation for 390 a realistic value of the shear band. The shear band thickness is an input parameter and it 391 does not depend on the mesh discretization. The strains, computed at material points, 392 according to the standard MPM procedure, are assumed to localize in the embedded shear 393 bands where the heat induced by frictional work dissipates and the induced liquid 
overpressure is generated. In terms of governing equations, embedded shear bands are included by formulating a local equilibrium of energy and mass between the embedded shear band and the rest of the domain.

In the case of Canelles landslide, the thickness of the shear bands generated in the Garumnian clay was estimated to be $2 \mathrm{~cm}$. For the rock, a larger value $(10 \mathrm{~cm})$ was selected. Changing these values by one order of magnitude did not result in significant changes of results.

\section{Initial and boundary conditions}

The initial stress state is defined by imposing a gradually increasing gravity loading.

Since the purpose of this paper is the analysis of the sliding motion once the instability was induced by a rapid reservoir drawdown, the initial conditions in terms of the pore water pressure distribution and water reservoir level correspond to the conditions explaining the slide reactivation calculated by means of the finite element analysis in Pinyol et al. (2012). In this paper, the pore water pressure distribution was estimated in Pinyol et al. (2012) by simulating four-year period of the reservoir operation and the average yearly rainfall. This pore water pressure distribution has not been calculated in MPM because it requires an expensive and time consuming calculation in the MPM-GEOPART code due to the explicit time integration of the code and the required small time step.

Therefore, the initial pore water pressure distribution inside of the slope, introduced as initial values in the material points, are the values calculated by means of the FEM code (Code_Bright) in the summer of 2006 at the end of the drawdown. In the MPM calculation, a quasi-static calculation of the gravity loading was first imposing to simulate an initial stress in equilibrium. At this stage, a horizontal phreatic surface at the same level of the reservoir water defines the pore pressure distribution inside the slope (Figure 10a). This initial condition corresponds to the situation before the drawdown of 2006. Once equilibrium is reached, in a second stage of MPM calculations, the pore pressure distribution and the reservoir level is suddenly imposed, following the conditions calculated for the summer of 2006 (Figure 10b). The slide becomes unstable at this point and motion initiates. 
422 Only positive values of pore water pressure are included and suction effects acting on the 423 non-saturated mobilized rock are neglected in this analysis.

\section{Results and discussion}

425 The imposed conditions in terms for reservoir water level and pore water pressure 426 distribution, representing the situation at the summer 2006 (Figure 10b), lead to the failure 427 of the slope for a constant residual frictional angle on the basal clayey layer of 11.5ㅇ. For 428 higher values, the slope remains in equilibrium, irrespective of thermal interactions.

\section{Heating and rate effects}

430 The rapid acceleration of landslides by thermal interactions in the shear band requires a

431 feedback mechanism. Let us imagine a situation of dynamic equilibrium of the landslide at 432 a given displacement rate (it may be zero: strict static equilibrium). Any external action, 433 typically a pore pressure increase, will induce an increase in the creeping rate. This new 434 creeping shearing rate introduces a heat increase in the band and a pore water pressure 435 increment which is also a result of the pressure dissipation, controlled by permeability. The 436 associated decrease in effective stress reduces the available strength and the unbalanced 437 driving force results in an increase in landslide velocity, an increase in work dissipation at 438 shear band level and a new increase in pore pressure and sliding velocity. In the absence of 439 any mechanism counteracting this feedback "loop" the slide accelerates and it reaches high 440 velocities in seconds.

441 However, there may be two counteracting mechanisms: (a) rate effects on friction are 442 capable of supressing the feedback because they increase the resistance forces and bring 443 back to zero the unbalanced forces in the slide, at the cost of a new and higher creeping 444 rate; (b) the motion of the slide may lead to a more stable situation due to changes in the 445 geometry of the slide (i.e. compound slides).

446 Seven cases were analysed under different hypotheses in order to investigate cross 447 interactions in the case of Canelles landslide. The first four cases do not consider strain 448 softening effects:

449 - Case 1: Thermal interaction allowed; no strain-rate hardening.

450 - Case 2: Thermal interaction allowed; strain-rate hardening activated. 
- Case 3: No thermal interaction; no strain-rate hardening.

- Case 4: No thermal interaction; strain-rate hardening activated.

Consider first Case 1. This case corresponds to the hypothesis assumed by Pinyol et al. (2012). In this case, thermal balance equations and their interaction with the motion are activated in the code. No strain rate effects are included and the frictional law remains at the residual value $\left(\phi_{r e s}^{\prime}=11.5^{\circ}\right)$. The rest of parameters are indicated in Table 2 .

The sudden change of boundary conditions (Figure 10) generates a short dynamic transient in the calculation. Once stabilized, the slide accelerates because of the thermal mechanisms developing on the sliding surface. As the frictional work dissipates in heat, the temperature and the pore water pressure in the sliding surface increase, the available strength decreases and the slide accelerates. The velocity increases up to $1.44 \mathrm{~m} / \mathrm{s}$ in 5 seconds. At a certain moment, the sliding velocity reduces due to the transfer of sliding mass to more stable positions in the lower part and the weight reduction over the steeper upper part of the slope. The slope becomes stable after $55 \mathrm{~m}$ of run-out (Figure 11). The pore water pressure increases, as show Figure 12a for three points along the sliding surface. The point P2 has a larger rock cover than points P1 and P3. The higher local dissipation of heat in point P2 explains the large excess pore pressure developed if compared with P1 and P2. The MPM results of Case 1 confirm the landslide response calculated in Pinyol et al. (2012) by using a simpler approach.

This result indicates the existence of a risk of acceleration due to the accumulation of thermal-induced excess pore water pressures. However, the actual slide displacement after its reactivation was no more than $50 \mathrm{~cm}$ (maximum opening observed in the perimeter crack).

When strain rate hardening is included in the calculation, the sliding motion evolution becomes very different. A Case 2 was run in which the strain rate effects are modelled according to Eq. (10) with $\phi_{r e s}^{\prime}=11.5^{\circ}, \bar{\phi}^{\prime}=2^{\circ}$ and $\alpha=10^{7}(1 / \mathrm{s})$. The accumulated displacement calculated for Case 1 and Case 2 are plotted in Figure 11 and Figure 13. The 
479 maximum displacement, measured at the toe of the slope, is now $6 \mathrm{~cm}$. This value is higher $480(15 \mathrm{~cm})$ in the upper part of the slope. In this case, the sliding velocity is always very small 481 and the motion does accelerate due to the increase of the frictional strength. This additional 482 strength allows maintaining the velocity small enough to avoid the accumulation of the 483 thermal-induced excess pore water pressures. Values of the pore water pressure 484 distribution for this case are plotted in Figure 12. The small excess pore pressure calculated 485 in this case for different points along the sliding surface (2 to $25 \mathrm{kPa}$; compare with Case 1), 486 implies a small reduction in available normal effective stress and therefore a small reduction 487 in resisting forces.

488 As analyzed in Alonso et al. (2016), for a certain combination of parameters and under the 489 assumption of a planar landslide, the mobilized mass may reach a constant low velocity. In 490 this regime, the relatively small excess pore pressure generated can dissipate and the 491 landslide does not accelerate. In the case of Canelles, such constant velocity is not even 492 reached due to of the effect of the geometry, described before. According to the results 493 (Figure 13), after $6 \mathrm{~cm}$ of displacement and 70 seconds of accelerated motion, the slope 494 becomes stable and stops. It is remarkable to find that a moderate strain rate effect (in 495 other formulations, a moderate viscous effect) succeeds to eliminate the blow-up risk 496 inherent to the thermal pressurization phenomena.

497 Results are sensitive to the values defining the strength. For a residual frictional angle of 49813 o the slope is stable under the drawdown condition. On the other hand, once it becomes 499 unstable, low values of the intensity of rate effects on friction leads to the accumulation of 500 creeping strains at an increasing rate which eventually will lead to blow-up conditions. This 501 type of behaviour was identified for the one dimensional case of a planar landslide by 502 Alonso et al (2016).

503 Results for Cases 3 and Case 4 were also plotted in Figures 11 and 13. These cases are 504 isothermal (the thermal interaction was not activated and the temperature was imposed 505 constant during the whole calculation). In Case 3 the frictional strength does not depend on 
506 the strain rate and in Case 4, the hardening friction law of Equation (10) was included with 507 the same parameters of Case 2.

508 The final displacement of Case 2 is larger than the values calculated for the isothermal case 509 (Cases 3 and 4) because of the development of (small) heat induced excess pore pressures 510 in the sliding surface, even if the sliding velocity remains within a creeping stage. Therefore, 511 the thermal interaction has an effect on the creeping velocity especially for low permeability 512 materials. This conclusion, which was also noticed in the analysis of Alonso et al. (2016) for 513 simple geometries involving one-dimensional conditions, is also found in the continuous 514 MPM solution for a realistic geometry based on a real case.

515 Figure 14 shows the final geometry of the landslide for Cases 1 and 2 and the contours of 516 equal accumulated displacements. The differences observed among Cases 2, 3 and 4 are 517 not significant in practice but this is a consequence of the geometry and material properties 518 of the case analyzed. In all cases not affected by blow-up conditions (Cases 2, 3 and 4) the 519 landslide comes to a rest because of geometrical considerations: mass transfer from the 520 upper to the lower levels. This result will not be the case in a planar landslide.

\section{$521 \quad$ Strain softening}

522 Strain softening effects analyzed here are related to mechanisms already mentioned: 523 change in straining rate (because of the reactivation of the slide) and gain in strength due 524 to a resting period. Experimental results on the second effect were reported by Stark and 525 Hussain (2010) and Carruba and Del Fabbro, 2008). The topic is, however, somewhat 526 controversial. In fact, Mesri \& Huvaj-Sarihan (2012) present a strong allegation and 527 supporting references against any increase in residual strength motivated by healing effects 528 for two main reasons: At the field scale, published analysis of slide reactivation shows no 529 increase in residual strength. At the laboratory scale, reported gains in strength are 530 attributed to experimental difficulties for the slip surface to remain undisturbed during 531 shearing. Nevertheless, the transient peak after slide reactivation, even if its intensity is 532 limited, may have an effect in the landslide reaction because of the intricate relations 533 among strain rate effects, thermal interactions, strain softening and changes in geometry.

534 The following three new cases provided additional information: 
The cases differ only in the adopted values for the peak and residual strengths (in parenthesis). A common $\eta$ value (see Equation 10), $\eta=50$ (Table 2), defines the rate of strength decay from peak to residual. Strain rate effects are maintained as in the previous reference cases.

544 Figures 11 and 13 show the calculated evolution of displacements for the three new cases 545 at two different scales. Cases 5 and 6 lead to the stabilization of the landslide and the 546 calculated maximum displacements are a little lower than displacements for Cases 2, 3 and 5474.

548 Consider first Case 5. Figure 15 shows the evolution of the friction angle. The fast initial 549 increase in velocity mobilizes the strain rate effects and the effective friction reaches a value 550 close to 13.5 , above the peak friction angle. As time evolves and the landslide geometry 551 moves into more stable configurations, the friction angle decreases, slowly at the beginning 552 and faster, but irregularly, later. It eventually reaches a constant value, around 11.5으, 0.5응 553 higher than the residual strength. The slide maintains a slow creeping motion.

554 Case 7 is different and strain rate effects on friction cannot avoid the "blowing-up" 555 mechanism leading to a rapid increase in pore pressures. The sliding velocity and run-out 556 increase fast and reach values similar to the first case analyzed (no rate effects and no strain 557 softening). The effective friction (Figure 15) is the result of strain softening and strain rate 558 effects. They operate in opposing sense. However, the small residual friction (10) is to be 559 compared with the best estimate for strict equilibrium: 11.5‥ This friction does not lead to 560 rapid motion if strain rate effects are introduced (Case 2). A 10 residual friction cannot 561 avoid the slide acceleration and the development of significant thermal effects. Peak 562 velocity is not as high as the values calculated for Case 1 because the rate effects are now 563 present and the operating friction reaches a value $12 \circ$ during most of the time. The $12 \circ$ 564 value is the sum of the 10 o of residual friction and the maximum allowed increase in rate 
565 effects on friction (2) because the landslide velocity is high. When thermal effects 566 dominates, strain rate effects play a minor role and the landslide would come to a stop 567 because of changes in landslide geometry. This is the case of Cases 1 and 2.

568 For the dimensions of the computational mesh (uniform cells of 2 by 4 meters), the 569 parameter $\eta=50$ means that residual conditions due to strain softening are reached for 570 relative shear displacements of 20 to $30 \mathrm{~cm}$. Therefore, for the small equilibrium 571 displacements calculated for Cases 5 and 6 (Figure 13), the operating friction angle remains 572 close to peak conditions ( $12 \circ$ and $13 \circ$ respectively).

\section{Conclusions}

575 The case described in the paper is a typical scenario often found by dam and reservoir 576 operators. Valley slope instability is a consequence of the pore pressure raise, because of 577 reservoir impounding of the slope toe.

578 Rapid drawdown is a critical condition which contributes to reduce the safety margin in the 579 presence of low permeability materials. This is the case of Canelles landslide, a reactivation 580 of a pre-existing landslide during a strong drawdown. In these cases, a frequent question 581 concerns the risk of a rapid failure and its consequences in reservoir margins and beyond.

582 A high sliding velocity after a previous slow creeping period may be explained by thermal 583 pressurization of the sliding surface if it is located in a low permeability clayey material. 584 However, cases of rapid sliding are not widespread. A physical reason to limit the 585 development of blow up conditions is the increasing resistance of sliding when creeping 586 rate increases. This resistance contribution is explained by strain rate effects on friction. In 587 this regard, long-term displacement records, closely correlated with rainfall-induced 588 changes in phreatic level, could be reproduced by a simple dynamic formulation of the 589 motion equation, including rate effects on friction of the sliding surface.

590 The paper describes the combined effects of thermal interaction and rate effects on friction 591 within the general framework of Material Point Method (MPM). The continuous nature of 592 MPM offers the possibility of analyzing real cases, characterized by arbitrary geometries 593 and soil layering. 
594 A recently developed MPM tool including thermal interaction and rate effects on friction

595 allowed a more realistic tool simulation of Canelles landslide evolution, if compared with 596 previous analyses performed in the domain of Finite Element analysis. It was found that the 597 sliding resistance enhancement provided by shearing rate effects even if it is small, 598 contributes to eliminate or to reduce the risk of a high, thermally driven, landslide velocity. 599 The physical background and the computational procedure described in the paper offer a 600 new perspective to evaluate, at an early (creeping) stage, the risk of a landslide evolving 601 toward a rapid and dangerous motion.

602 In the absence of blow-up conditions, thermal interaction also contributes to increase the 603 creeping motion because of the generation of (small) excess pore pressures in the shear 604 band.

605 The analysis developed includes also strain softening effects on the residual friction. They 606 may be significant during the early stages of slide instability. The development of a peak 607 friction may be explained by healing effects in case of a slide reactivation and, also, by the 608 transient increase in deformation rates.

609 The relationship between creeping states and fast-accelerated landslide motion is a 610 complex phenomenon. Main controlling factors are the landslide geometry, internal 611 kinematic constraints, the permeability of the soil in the vicinity of the sliding surface, the 612 available increase in friction induced by shearing rate effects, strain softening of residual 613 strength and the intensity of the external actions (i.e. a change of water level) triggering the 614 instability. The proposed model offers the possibility of integrating them in the analysis.

\section{ACKNOWLEDGEMENTS}

616 The authors acknowledge the financial support to CIMNE by the CERCA 617 Programme/Generalitat de Catalunya and AEI and FEBER. The first and the second authors 618 also acknowledge the fellowship IJCl-2015-26342 and scholarship BES-2014-068284, 619 respectively, from AEI (Agencia Estatal de Investigación), FEBER and the Spanish 620 Government. 
622

623

624

625

626

627

628

629

630

631

632

633

634

635

636

637

638

639

640

641

642

643

644

645

646

647

648

649

650

\section{REFERENCES}

Alonso, E.E., Zervos, A. \& Pinyol, N.M., 2016. Thermo-poro-mechanical analysis of landslides: from creeping behaviour to catastrophic failure. Geotechnique 66(3), pp.202-219

Alvarado, M., 2018. Landslide motion assessment including thermal interaction. An MPM approach. PhD Thesis. Universitat Politecnica de Catalunya, Barcelona, Spain.

Angeli, M.-G. et al., 1996. A visco-plastic model for slope analysis applied to a mudslide in Cortina d'Ampezzo, Italy. Quarterly Journal of Engineering Geology, 29, pp.233-240.

Bandara S.S., Ferrari A., Laloui L., 2016. Modelling landslides in unsaturated slopes subjected to rainfall infiltration using material point method. International Journal for Numerical and Analytical Methods in Geomechanics 40(9), 1358-1380.

Bardenhagen, S.G., Brackbill, J.U. \& Sulsky, D., 2000. The material-point method for granular materials. Computer Methods in Applied Mechanics and Engineering, 187(3-4), pp.529-541.

Bowden, F. \& Tabor, D., 1964. The friction and lubrication of solids, New York: Oxford University Press.

Carrubba, P., Del Fabbro, M. D. 2008. Laboratory investigation on reactivated residual strength. J. Geotech. Geoenviron. Eng., 134(3), 302-315.

Cascini, L., Calvello, M., Grimaldi, G.M., 2010. Groundwater modeling for the analysis of active slow-moving landslide. Jounal fo Geotechnical and Geoenvironmental Engineering, 136 (9), pp. 1220-1230.

Ceccato F., 2017. Run-up of granular avalanches on protective barriers: a numerical study with the Material Point Method. 15th IACMAG, 19-23 October 2017, Wuhan, China.

Ceccato, F., Simonini, P., 2016. Study of landslide run-out and impact on protection structures with the material point method. Interpraevent Congress, 30 May-2 June 2016, Lucerne, Suisse.

Cecinato, F., Zervos, A. \& Veveakis, E., 2011. A thermo-mechanical model for the catastrophic collapse of large landslides. International Journal for Numerical Methods in Engineering, 35(September 2010), pp.1507-1535. 
651 Code_Bright (2018) https://deca.upc.edu/en/projects/code_bright

652 Corominas, J., Moya, J., Ledesma, A., Lloret, A., Gili, J.A., 2005. Prediction of ground 653 displacements and velocities from groundwater level changes at the Vallcebre 654 landslide (Eastern Pyrenees, Spain). Landslides, 2(2), pp.83-96.

655 Davis, R.O., Desai, C.S. \& Smith, N.R., 1993. Stabiltiy of motions of translatinoal landslide. J. 656 Geotech. Engng, 119(3), pp.420-432.

Di Toro, G., Hirose, T., Nielsen, S., Pennacchioni, G., Shimamoto, T., 2006. Natural and 658 659 experimental evidence of melt lubrication of faults during earthquakes. Science (New 660 York, N.Y.), 311(February), pp.647-649.

Dieterich, J., 1979. Modeling of rock friction I. Experimental results and constitutive 661 equations. J. Geophys. Res., 84(5b), pp.2161-2168.

Goren, L. \& Aharonov, E., 2007. Long runout landslides: The role of frictional heating and 663 hydraulic diffusivity. Geophysical Research Letters, 34, pp.1-7.

Goren, L. \& Aharonov, E., 2009. On the stability of landslides: A thermo-poro-elastic 665 approach. Earth and Planetary Science Letters, 277(3-4), pp.365-372.

Habib, P., 1975. Production of gaseous pore pressure during rock slides. Rock Mech. Rock 667 Engng., 7(4), pp.193-197.

Hendron, A.J. \& Patton, F.D., 1985. The Vaiont slide, a geotechnical analysis based on new 669 geological observations of the failure surface. Vol. II. Technical Report GL-85-5,

International Union of Geological Sciences/International Working Group on Landslides, 1995. A suggested method for describing the rate of movement of a landslide. Bull. Int. Assoc. Engng. Geol., 52, pp.75-78.

Ledesma, A., Corominas, J., Gonzàles, A., Ferrari, A. 2009. Modelling slow moving landslides controlled by rainfall. In Proc 1st Ital Work Landslides. Napoli, Italy, p. Vol. 1, 196-205. Liao, C., Lee, D., Wu, J., Lai, C., 2011. A new ring-shear device for testing rocks under high normal stress and dynamic conditions. Engineering Geology, 122(1-2), pp.93-105. and Mobilized in Landslides. Journal of Geotechnical and Geoenvironmental Engineering, Vol. 138, No. 5,585-593 
680

681

682

683

684

685

686

687

688

689

690

691

692

693

694

695

696

697

698

699

700

701

702

703

704

705

706

707

708

Mitchell, J.K., 1976. Fundamentals of Soil Behavior, New York, USA: John Wiley \& Sons.

Olivella, S., Gens, A., Carrera, J., Alonso, E., 1996. Numerical formulation for a simulator (CODE_BRIGHT) for the coupled analysis of saline media. Engineering Computations, 13(7), pp.87-112.

Panizza, M., Pasuto, A., Silvano, S., Soldati, M., 1996. Temporal occurrence and activity of landslides in the area of Cortina d'Ampezzo (Dolomites, Italy). Geomorphology, 15(34), pp.311-326.

Potts, D. \& Gens, A. (1985). A critical assessment of methods of correcting for drift from the yield surface in elasto-plastic finite element analysis. Numer. Analyt. Methods Geomech. 9, No. 2, 149-159

Pinyol, N.M., Alonso, E., Corominas, J., Moya, J., 2012. Canelles landslide: modelling rapid drawdown and fast potential sliding. Landslides, 9(1), pp.33-51.

Pinyol, N.M., Alonso, E., Corominas, J., Moya, J., 2016. Discussion on “ Large landslides associated with a diapiric fold in Canelles reservoir ( Spanish Pyrenees ): Detailed geological - geomorphological mapping , trenching and electrical resistivity imaging " by Gutiérrez et al . ( 2015 ). Geomorphology 263, pp.170-174.

Pinyol, N.M., Alvarado, M., Alonso, E.E., Zabala, F., 2018. Thermal effects in landslide mobility. Géotechnique 68(6), pp.528-545.

Pinyol, N.M. \& Alonso, E.E., 2010a. Criteria for rapid sliding II. Thermo-hydro-mechanical and scale effect in Vaiont case. Engineering Geology, 114(3-4), pp.211-227.

Pinyol, N.M. \& Alonso, E.E., 2010b. Fast planar slides. A closed-form thermo-hydromechanical solution. International Journal for Numerical and Analytical Methods in Geomechanics, 34, pp.27-52.

Rice, J.R. \& Ruina, a. L., 1983. Stability of Steady Frictional Slipping. Journal of Applied Mechanics, 50(2), p.343.

Ruina, A., 1983. Slip instability and state variable friction laws. J. Geophys. Res., 8(B12), pp.10359-10370.

Schulz, W.H. \& Wang, G., 2014. Residual shear strength variability as a primary control on movement of landslides reactivated by earthquake-induced ground motion: 
Implication for coastal Oregon, U.S. Journal of Geophysical Research: Earth Surface, 119, pp.1617-1635.

Skempton, A.W., 1985. Residual strength of clays in landslides, folded strata, and the laboratory. Géotechinque, 35(1), pp.3-18.

Stark, T.D., Hussain, M. 2010. Shear strength in pre-existing landslides. J. Geotech. Geoenv. Engng. 136(7): 957-962.

Soga K., Alonso E., Yerro A., Kumar K., Bandara S., 2016. Trends in large-deformation analysis of landslide mass movements with particular emphasis on the material point method. Géotechnique 66(3), pp. 248-273.

Sulsky, D. \& Schreyer, H.L., 1996. Axisymmetric form of the material point method with applications to upsetting and Taylor impact problems. Computer Methods in Applied Mechanics and Engineering, 139(1-4), pp.409-429.

Tika, Th.E., Vaughan, P.R. \& Lemos, L.J. 1996. Fast shearing of pre-existing shear zones in soil. Géotechnique 46(2): 197-233.

Tika, T.E. \& Hutchinson, J.N., 1999. Ring shear tests on soil from the Vaiont landslide slip surface. Géotechinque, 49(1), pp.59-74.

Uriel Romero, S. \& Molina, R., 1977. Kinematic aspects of Vaiont slide. In Proceedings of the 3rd international conference of the ISRMR. Denver, CO, USA: National Academy of Sciences 2B, pp. 865-870.

Vardoulakis, I., 2000. Catastrophic landslides due to frictional heating of the failure plane. Mech. Cohesive-frictional Mater., 5(6), pp.443-467.

Vardoulakis, I., 2002. Dynamic thermo-poro-mechanical analysis of catastrophic landslides. Géotechnique, 52(3), pp.157-171.

Veveakis, E., Vardoulakis, I. \& Di Toro, G., 2007. Thermoporomechanics of creeping landslides: The 1963 Vaiont slide, northern Italy. Journal of Geophysical Research, 112(F3), p.F03026.

Voight, B. \& Faust, C., 1982. Frictional heat and strength loss in some rapid landslides. Géotechnique, 32, pp.43-54.

Vulliet, L., \& Hutter, K., 1988. Viscous-type sliding laws for landslides. Can. Geotech. J., 25, 
467-477.

Wang, G., Suemine, A. \& Schulz, W.H., 2010. Shear-rate-dependent strength control on the dynamics of rainfall-triggered landslides, Tokushima Prefecture, Japan. Earth Surface Processes and Landforms, 35(4), pp.407-416.

Wedage, A., Morgenstern, N.R. \& Chan, D.H., 1998a. Simulation of time-dependent movements in syncrude tailings dyke foundation. Canadian Geotechnical Journal, 35, pp.284-298.

Wedage, A., Morgenstern, N.R. \& Chan, D.H., 1998b. A strain rate dependent constitutive model for clays at residual strength. Canadian Geotechnical Journal, 35, pp.364-373.

Yang, C. et al., 2014. Initiation , movement, and run-out of the giant Tsaoling landslide What can we learn from a simple rigid block model and a velocity - displacement dependent friction law ? Engineering Geology, 182, pp.158-181. A

Yerro, A., Alonso, E.E. \& Pinyol, N.M., 2015. Run-out of landslides in brittle soils: An MPM analysis. In Geomechanics from Micro to Macro - Proceedings of the TC105 ISSMGE International Symposium on Geomechanics from Micro to Macro, IS-Cambridge 2014. pp. 977-982.

Yerro, A., Pinyol, N.M. \& Alonso, E.E., 2015. Internal Progressive Failure in Deep-Seated Landslides. Rock Mechanics and Rock Engineering, 61(9), pp.795-808.

Zabala, F. \& Alonso, E.E., 2011. Progressive failure of Aznalcóllar dam using the material point method. Géotechnique, 61(9), pp.795-808.

Zabala, F., Rodari, R. \& Oldecop, L., 2004. Localización de deformaciones en estructuras utilizando el Método del Punto Material. Revista Engenharia Estrutural. 
761

762 Tables

763

764

Table 1. Geometry and material parameters for the two slides indicated.

\begin{tabular}{lcccccc}
\hline Slide & $\begin{array}{c}\text { Depth of the } \\
\text { sliding } \\
\text { surface, } \mathrm{D} \\
{[\mathrm{m}]}\end{array}$ & $\begin{array}{c}\text { Natural soil } \\
\text { density } \\
{[\mathrm{g} / \mathrm{cm} 3]}\end{array}$ & $\begin{array}{c}\text { Slope and sliding } \\
\text { surface } \\
\text { inclination, } \beta\left[^{\circ}\right]\end{array}$ & $\begin{array}{c}\text { Minimum } \\
\text { friction angle } \\
{\left[{ }^{\circ}\right]}\end{array}$ & $\begin{array}{c}\text { Maximum } \\
\text { friction angle } \\
{\left[{ }^{\circ}\right]}\end{array}$ & $\begin{array}{c}\text { Parameter } \\
\chi[\mathrm{s} / \mathrm{m}]\end{array}$ \\
\hline Alverà & 5 & 1,870 & 11 & 17 & 21.8 & $1.15 \cdot 10^{8}$ \\
Vallcebre & 15.4 & 2,100 & 6.5 & 7.8 & 11.8 & $3.85 \cdot 10^{7}$ \\
\hline
\end{tabular}

765

766 
Table 2. Constitutive parameters for the materials involved in Canelles landslide.

\begin{tabular}{|c|c|c|c|}
\hline Parameters & Symbol & Value & Units \\
\hline \multicolumn{4}{|c|}{ Water } \\
\hline Density & $\rho_{L}$ & 1000 & $\mathrm{~kg} / \mathrm{m} 3$ \\
\hline Bulk modulus & $\alpha_{L}$ & 2200 & $\mathrm{MPa}$ \\
\hline $\begin{array}{l}\text { Thermal dilation } \\
\text { coefficient }\end{array}$ & $\beta_{L}$ & $3.4 \mathrm{E}-4$ & $1 /{ }^{\circ} \mathrm{C}$ \\
\hline Thermal conductivity & $\Gamma$ & 0.58 & $\mathrm{~W} /\left(\mathrm{m} \cdot{ }^{\circ} \mathrm{K}\right)$ \\
\hline Specific heat & $c_{L}$ & $\begin{array}{c}4186 \\
1\end{array}$ & $\begin{array}{c}\mathrm{N} \cdot \mathrm{m} /\left(\mathrm{kg} \cdot{ }^{\circ} \mathrm{C}\right) \\
\mathrm{cal} /\left(\mathrm{kg} \cdot{ }^{\circ} \mathrm{C}\right)\end{array}$ \\
\hline \multicolumn{4}{|c|}{ Solid particles } \\
\hline Density & $\rho_{S}$ & 2700 & $\mathrm{~kg} / \mathrm{m} 3$ \\
\hline $\begin{array}{l}\text { Thermal dilation } \\
\text { coefficient }\end{array}$ & $\beta_{S}$ & $3.0 \mathrm{E}-5$ & $1 /{ }^{\circ} \mathrm{C}$ \\
\hline Thermal conductivity & $\Gamma$ & 0.375 & $\mathrm{~W} /(\mathrm{m} \cdot \mathrm{K})$ \\
\hline Specific heat & $c_{S}$ & $\begin{array}{c}837 \\
0.2\end{array}$ & $\begin{array}{c}\mathrm{N} \cdot \mathrm{m} /\left(\mathrm{kg} \cdot{ }^{\circ} \mathrm{C}\right) \\
\mathrm{cal} /\left(\mathrm{kg} \cdot{ }^{\circ} \mathrm{C}\right)\end{array}$ \\
\hline \multicolumn{4}{|c|}{ Clay Soil } \\
\hline Porosity & $n$ & 0.2 & - \\
\hline Permeability & $k$ & $1.00 \mathrm{E}-8$ & $\mathrm{~m} / \mathrm{s}$ \\
\hline Young's Modulus & $E$ & 500 & $\mathrm{MPa}$ \\
\hline Poisson's ratio & $v$ & 0.3 & - \\
\hline $\begin{array}{l}\text { Residual friction. Back } \\
\text { analysis }\end{array}$ & $\phi_{r e s}^{\prime}$ & 11.5 & $\circ$ \\
\hline Peak/Residual friction & $\phi_{p}^{\prime} / \phi_{r e s}^{\prime}$ & $12 / 11 ; 13 / 10 ; 12 / 10$ & $\circ$ \\
\hline Parameter (eq. 10) & $\eta$ & 50 & - \\
\hline Shear band thickness & e & 2 & $\mathrm{~cm}$ \\
\hline Parameter (eq. 10) & $\bar{\phi}$ & 2 & ○ \\
\hline Parameter (eq. 10) & $\alpha$ & $10^{7}$ & $1 / \mathrm{s}$ \\
\hline \multicolumn{4}{|c|}{ Siltstones and limestone } \\
\hline Porosity & $n$ & 0.3 & - \\
\hline Permeability & $k$ & $1.00 \mathrm{E}-6$ & $\mathrm{~m} / \mathrm{s}$ \\
\hline Young's Modulus & $E$ & 2500 & $\mathrm{MPa}$ \\
\hline Poisson's ratio & $v$ & 0.3 & - \\
\hline $\begin{array}{l}\text { Effective cohesion, } \\
\text { Peak, residual }\end{array}$ & $c_{p}^{\prime} / c_{r e s}^{\prime}$ & $1000 / 500$ & $\mathrm{kPa}$ \\
\hline $\begin{array}{l}\text { Effective friction. } \\
\text { Peak, residual }\end{array}$ & $\phi_{p}^{\prime} / \phi_{r e s}^{\prime}$ & $35 / 32$ & $\circ$ \\
\hline Shear band thickness & $\mathrm{e}$ & 10 & $\mathrm{~cm}$ \\
\hline
\end{tabular}




\section{Figures}
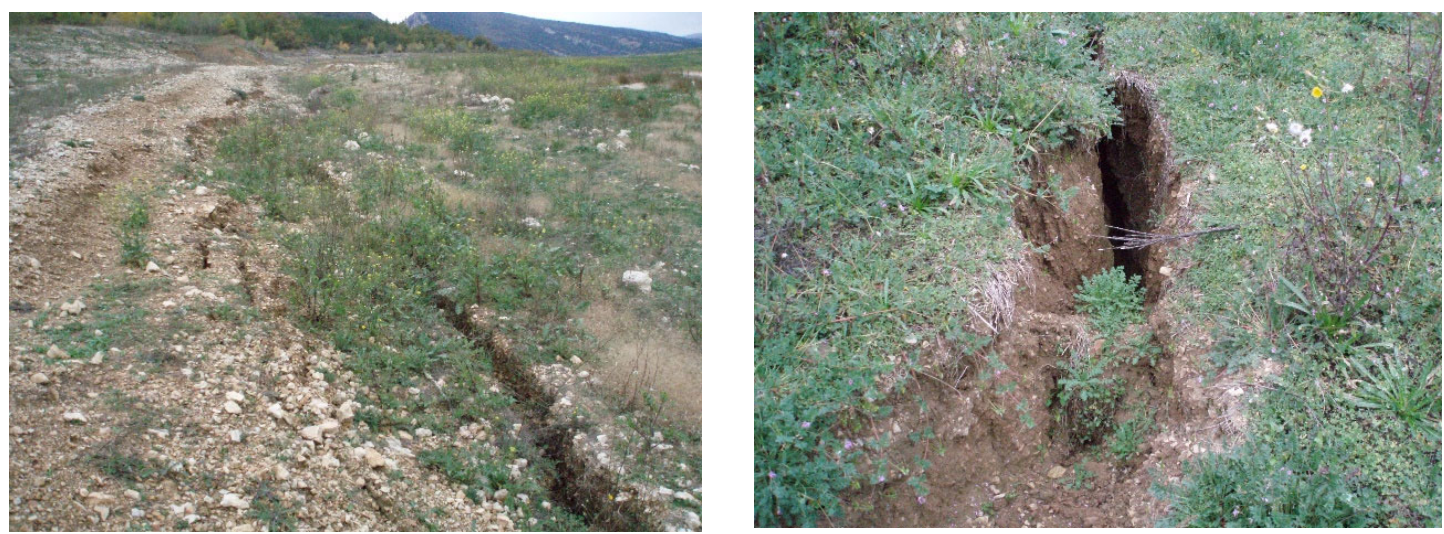

Figure 1. Tension crack of Canelles landslide upper limit in 2006.

771

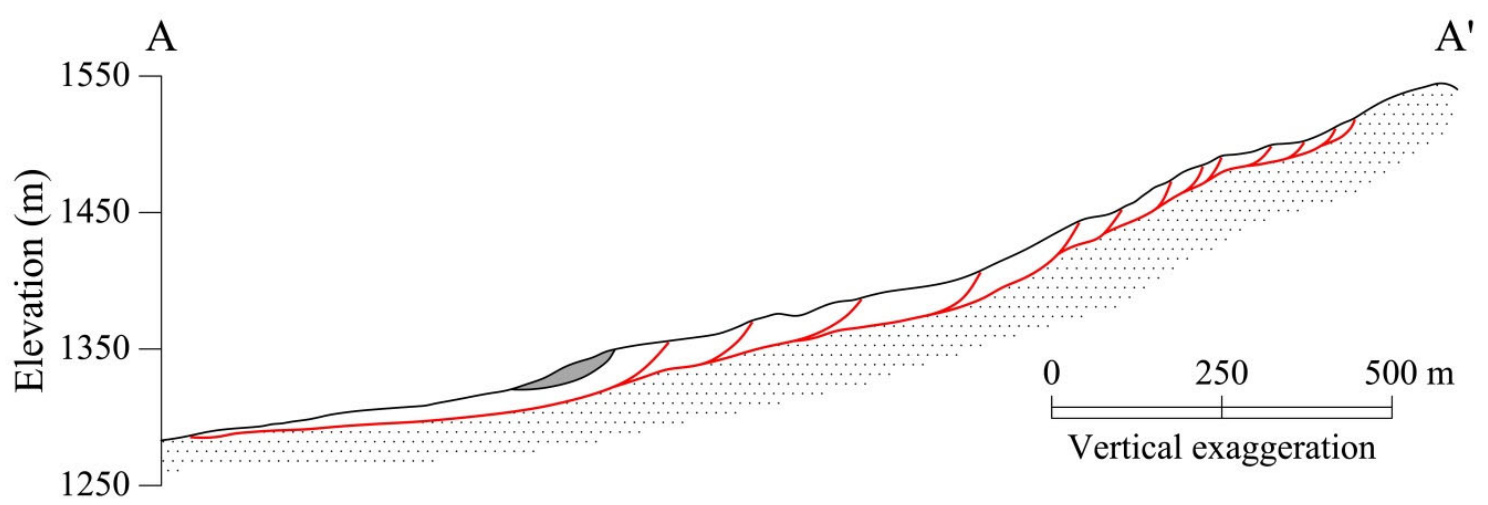

Figure 2. Representative slide section of Alverà slide (modified from Angeli et al. (1996)).
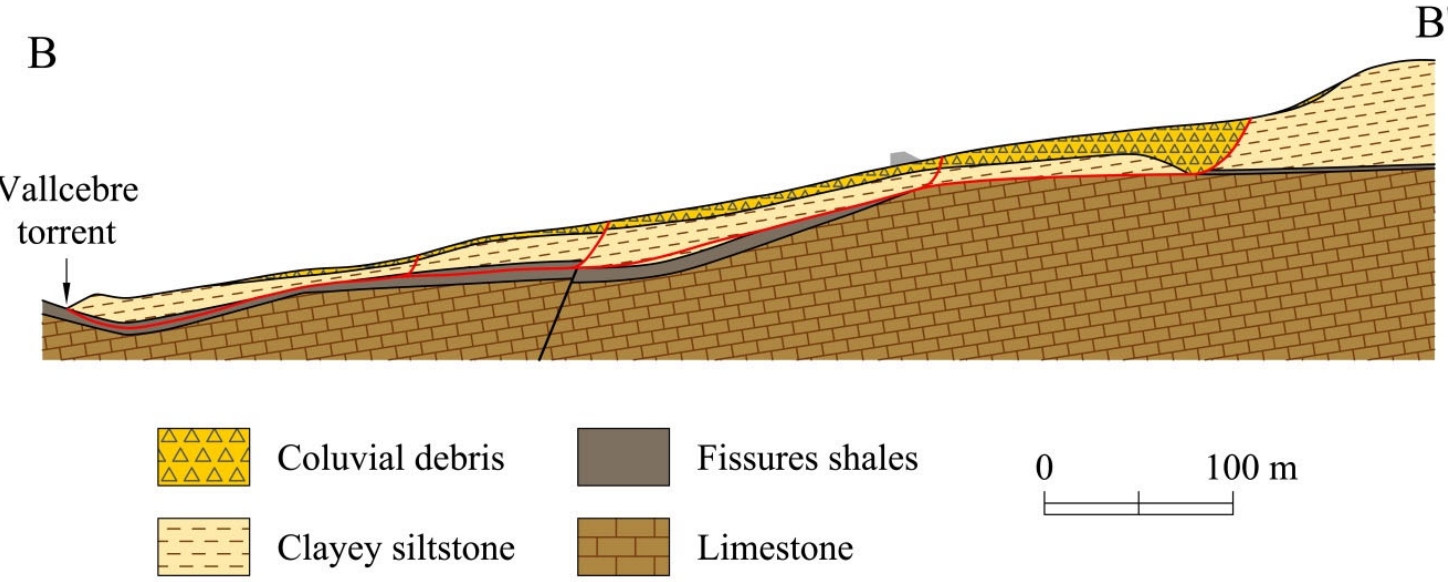

Figure 3. Representative cross section of Vallcebre landslide (Corominas et al. 2005). 
778

779

780

781

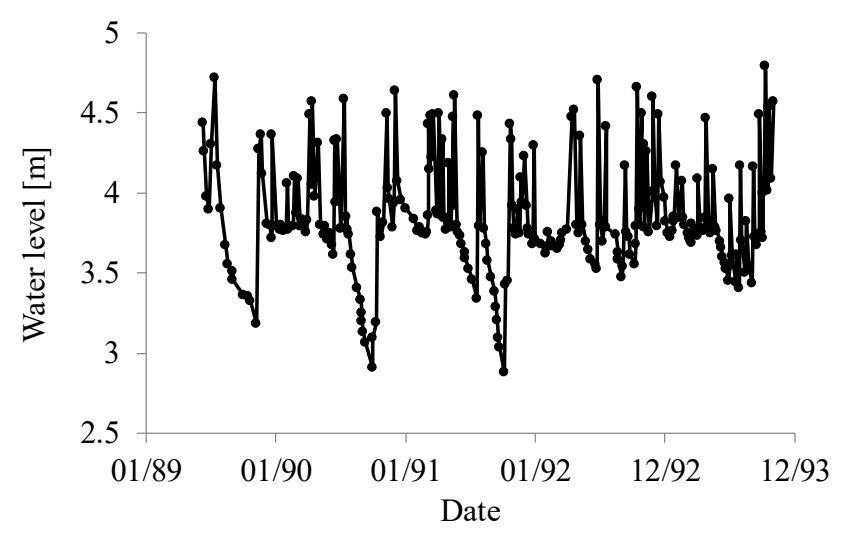

(a)

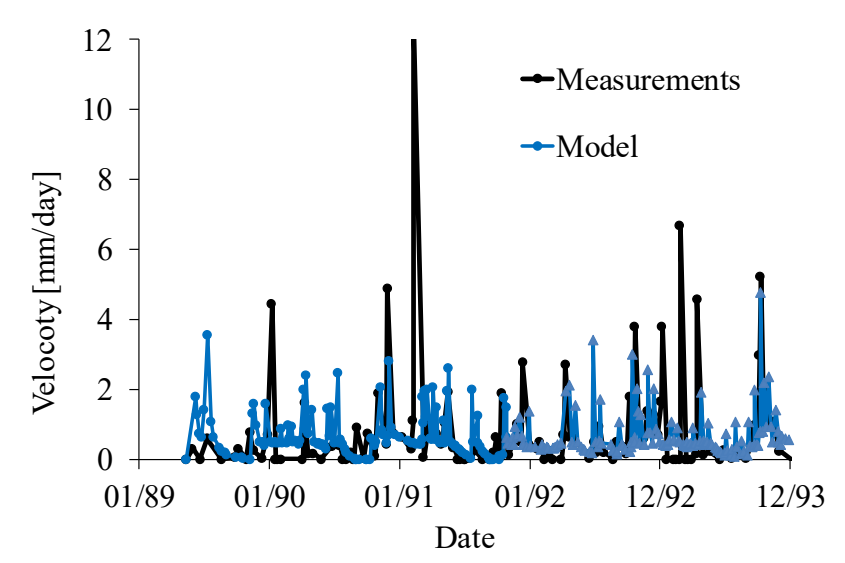

(b)

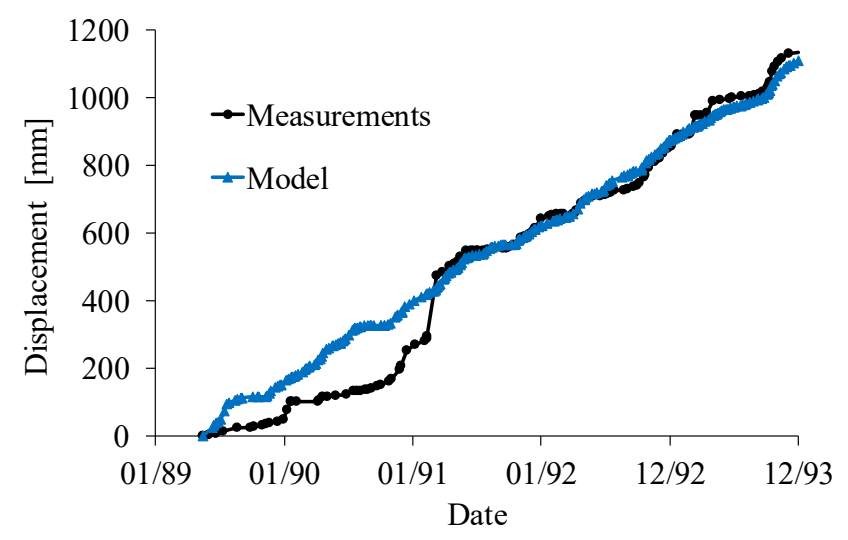

(c)

Figure 4. Measured and computed values of (a) height of the water level; (b) slide velocity; and (c) accumulated displacement in case of Alverà slide. 


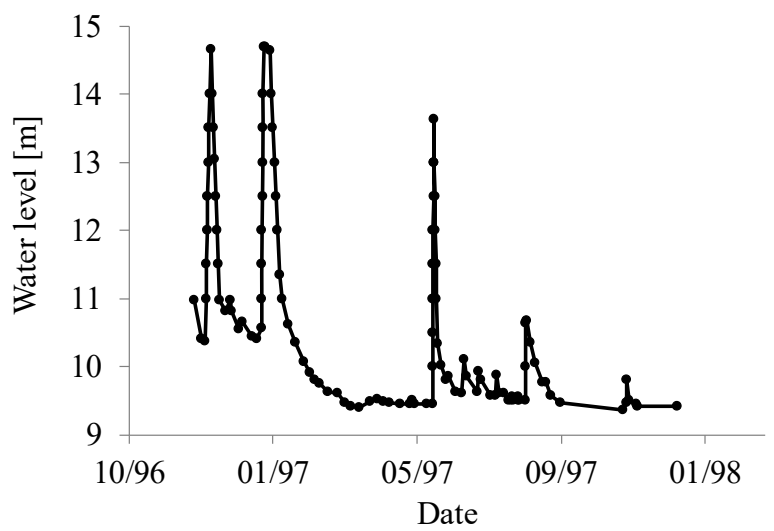

(a)
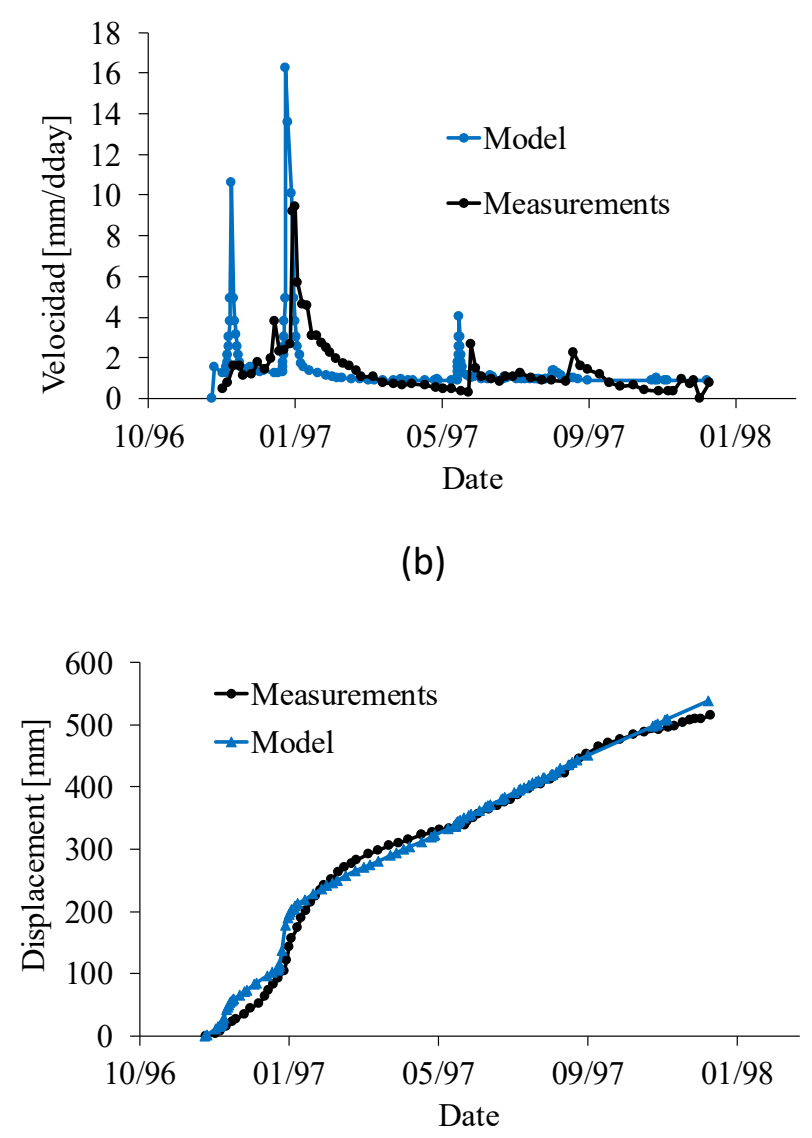
accumulated displacement in case of Vallcebre landslide. 


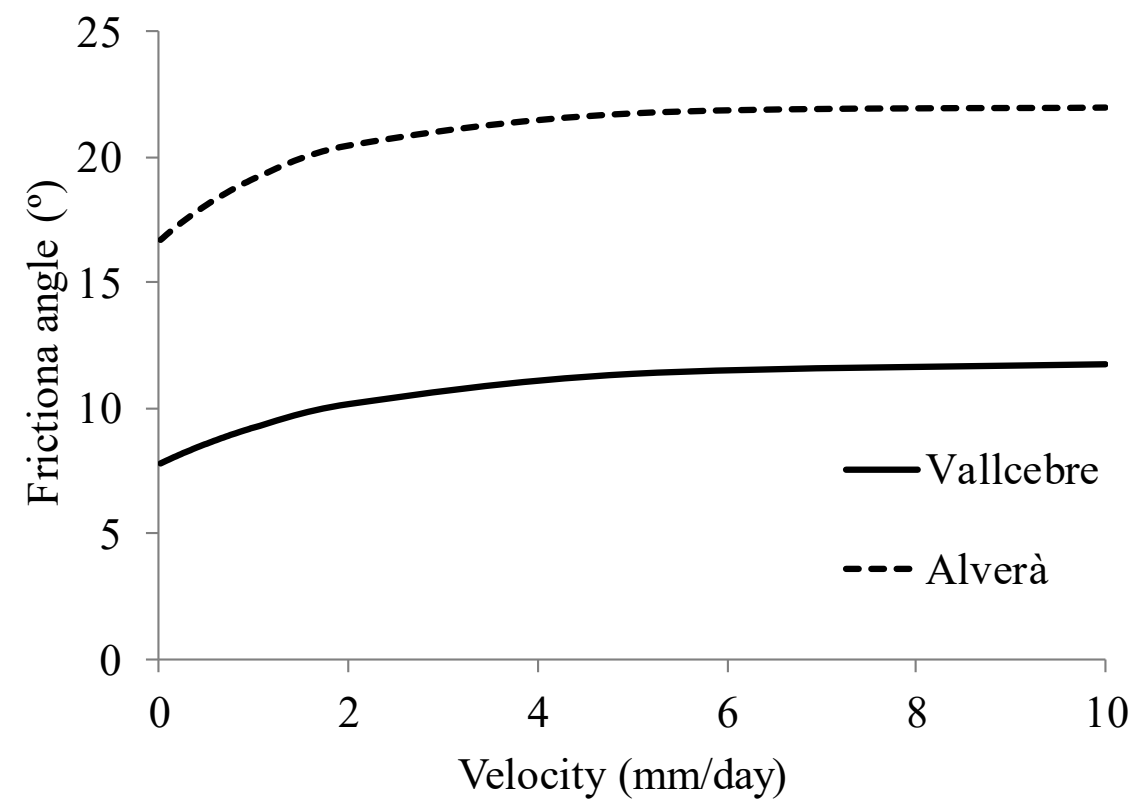

794

Figure 6. Variation of friction angle with sliding velocity for the cases analysed.

796

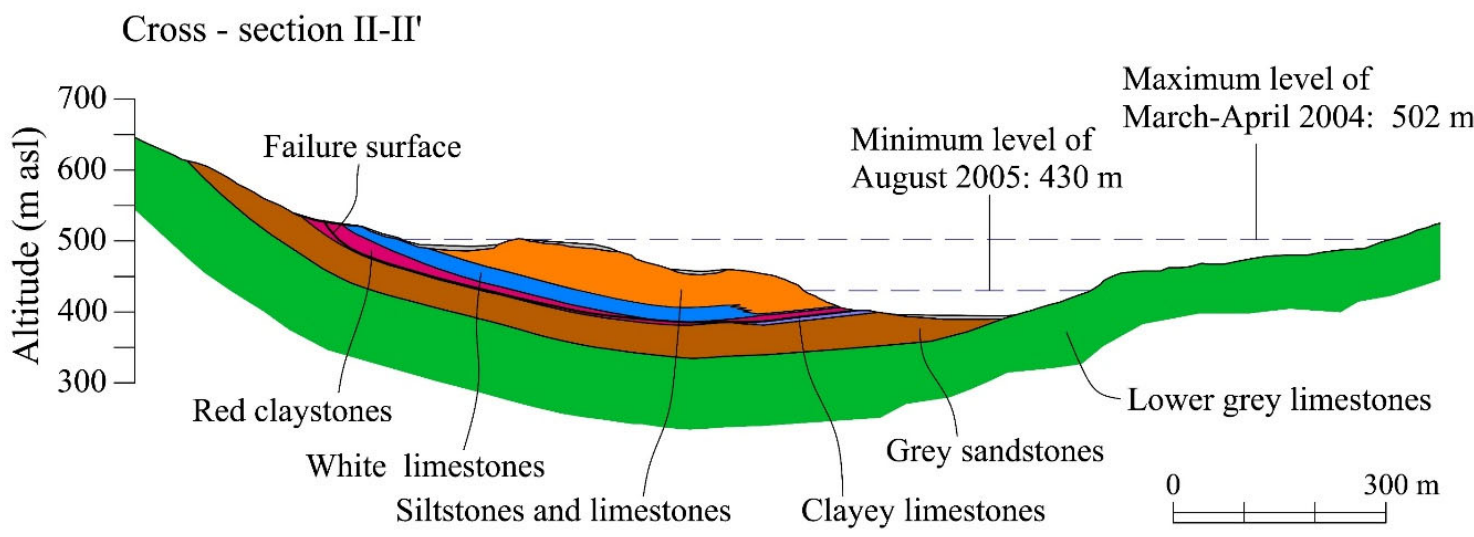

798

Figure 7. Central cross section of Canelles landslide (Pinyol et al. 2012).

799

800 


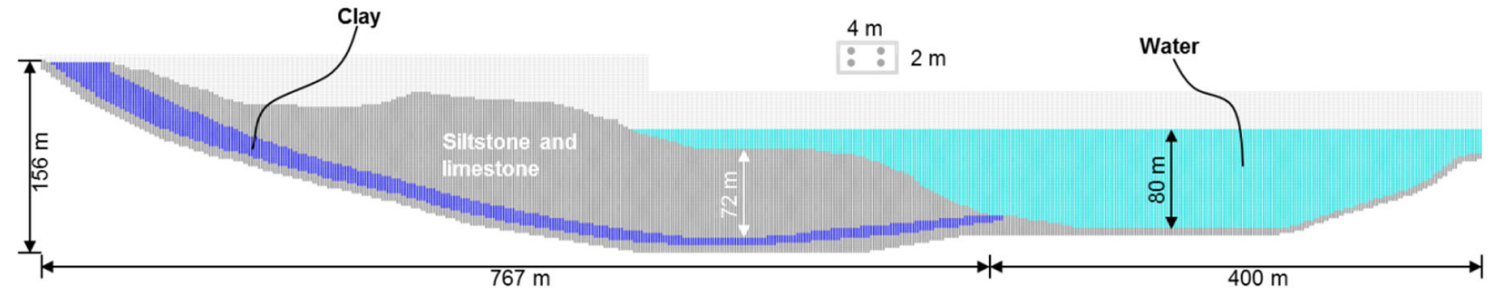

802

Figure 8. MPM discretization of Canelles landslide: computational mesh and material points. Rapid 803 drawdown reduced the water level indicated by $50 \mathrm{~m}$.

804 


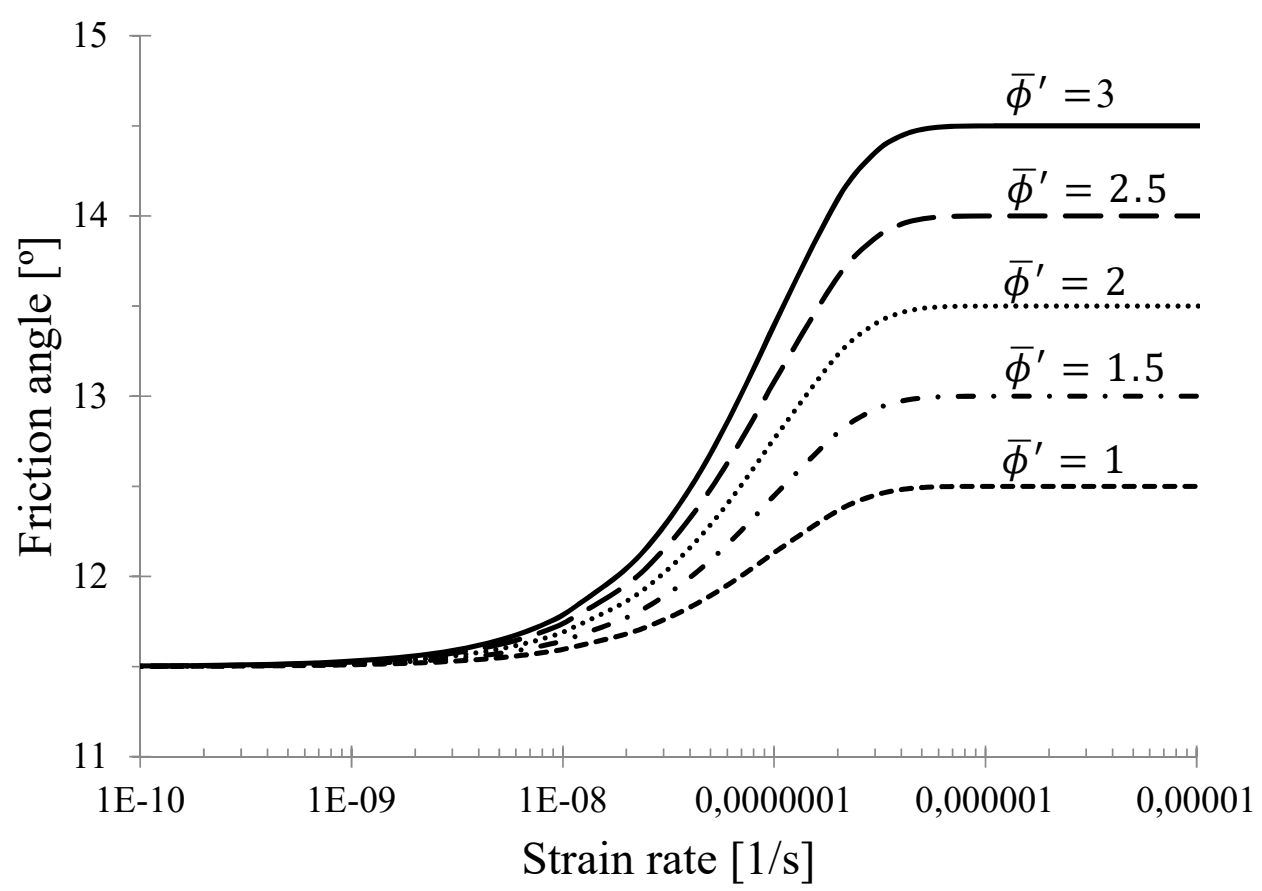

805

806

(a)

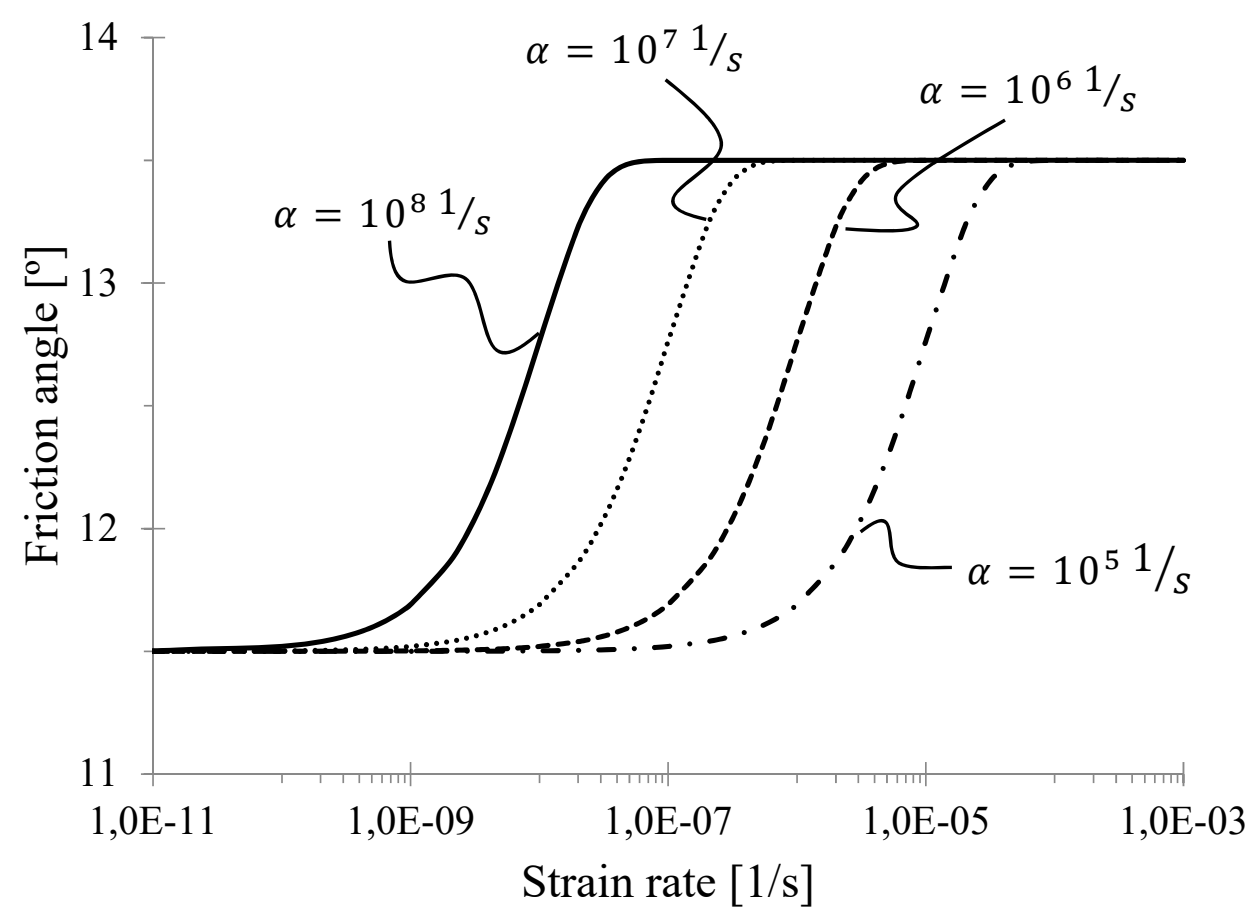

(b)

809 Figure 9. (a) Variation of friction angle with strain rate for $\alpha=10^{7}$ for different values of $\bar{\phi}^{\prime}$; (b) Variation of 810 friction angle with strain rate for $\bar{\phi}^{\prime}=2$ and different values of $\alpha$. 
Pore water pressure $[\mathrm{kPa}]$

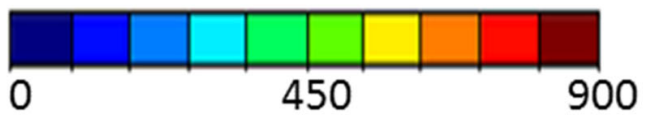

812

813

(a)

814

815

(b)

816 Figure 10. Water pressure distribution inside the landslide (a) before and (b) after the drawdown leading to 817 slide reactivation and reservoir level of MPM calculation.

818 


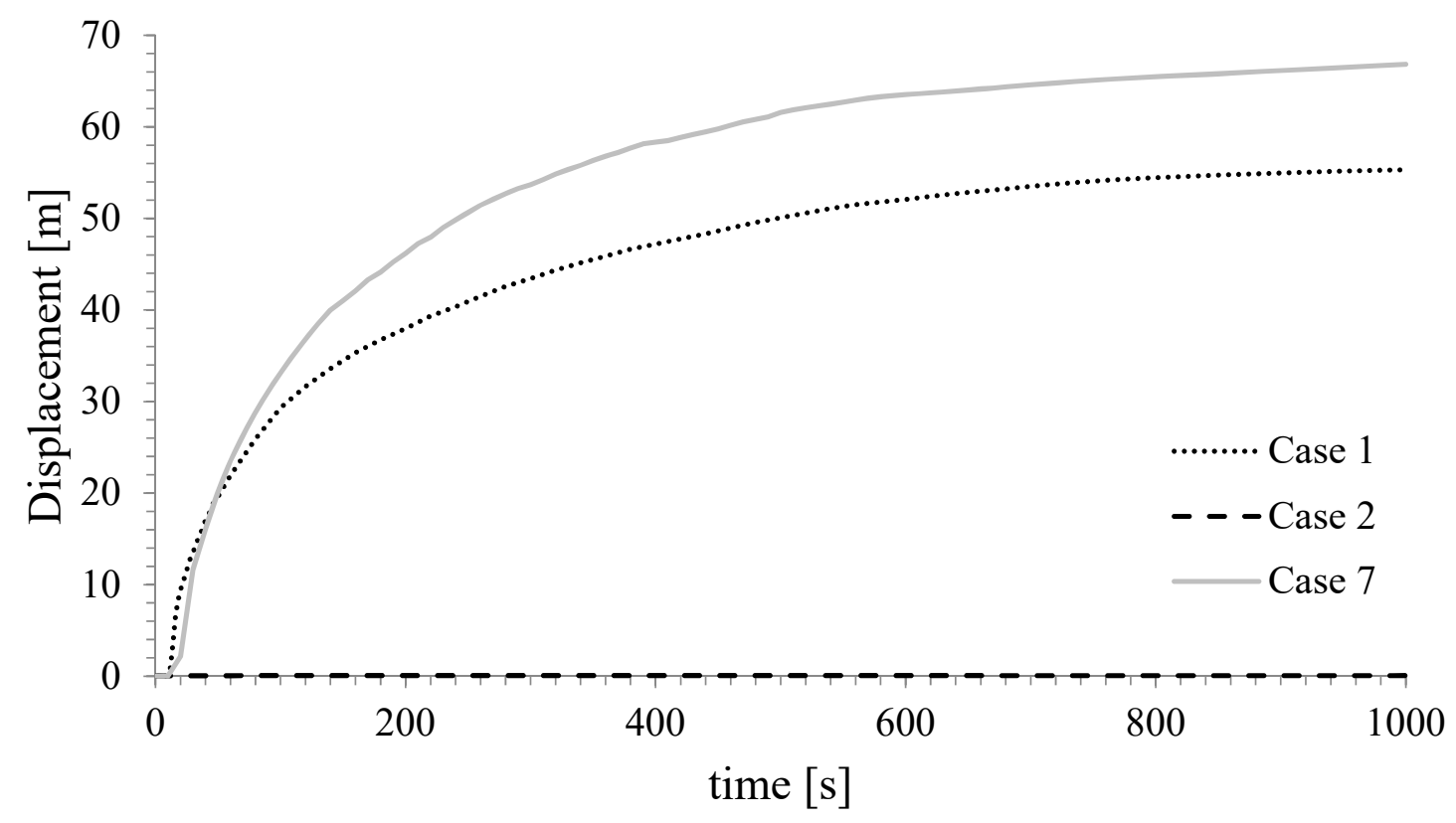

819

820

(a)

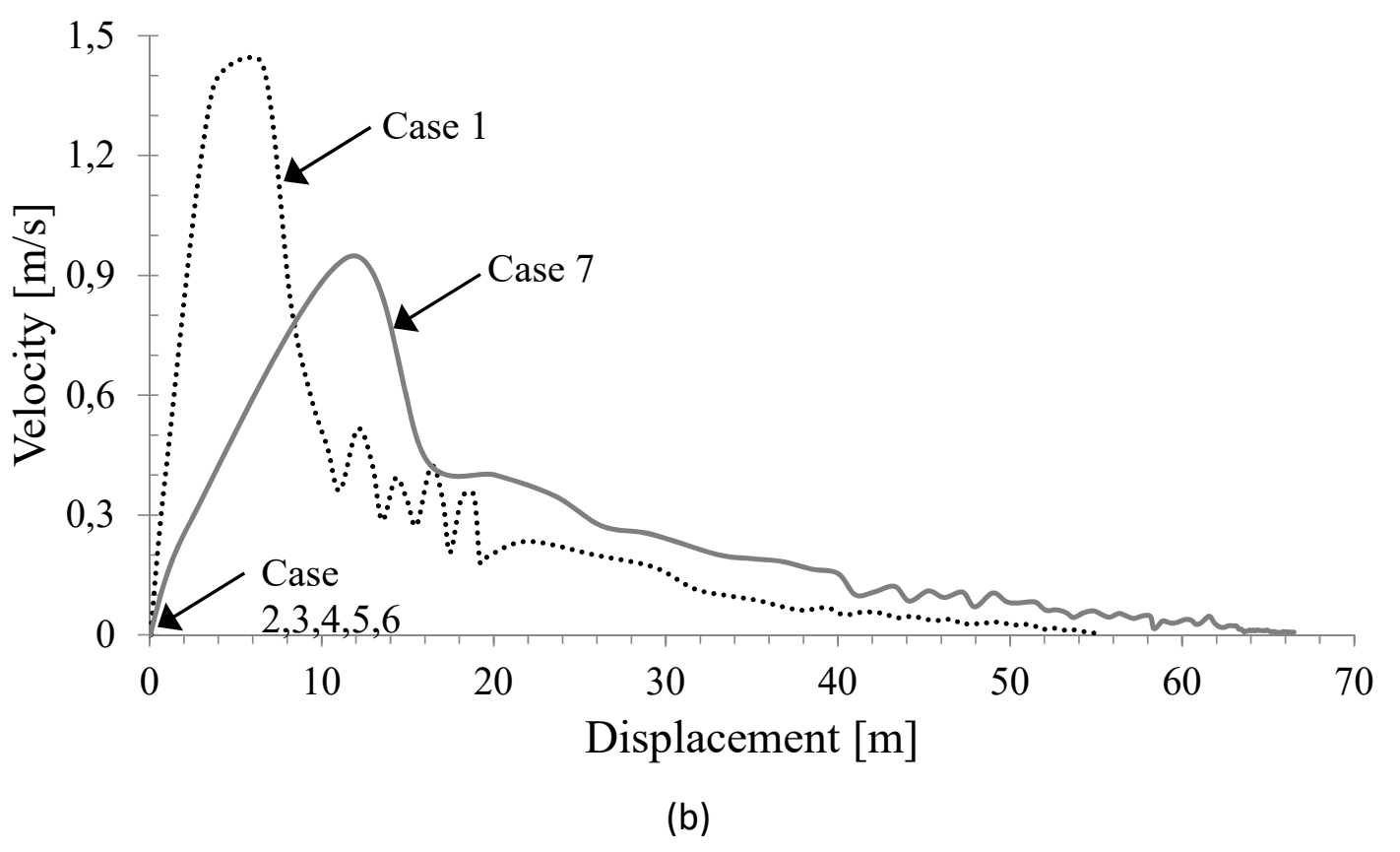

823 Figure 11. Evolution of (a) accumulated displacement in time and (b) velocity with displacements of the toe 824 of the landslide for Cases 1, 2 and 7.

825 

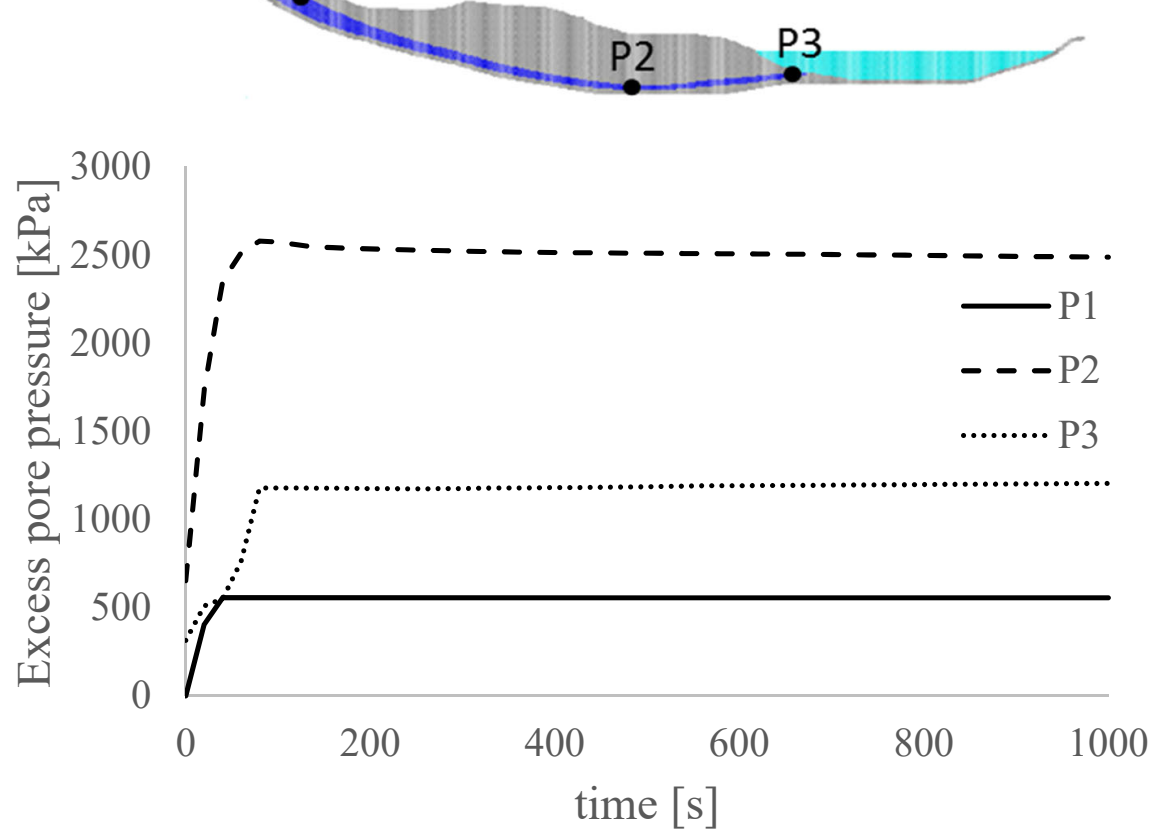

827

(a)

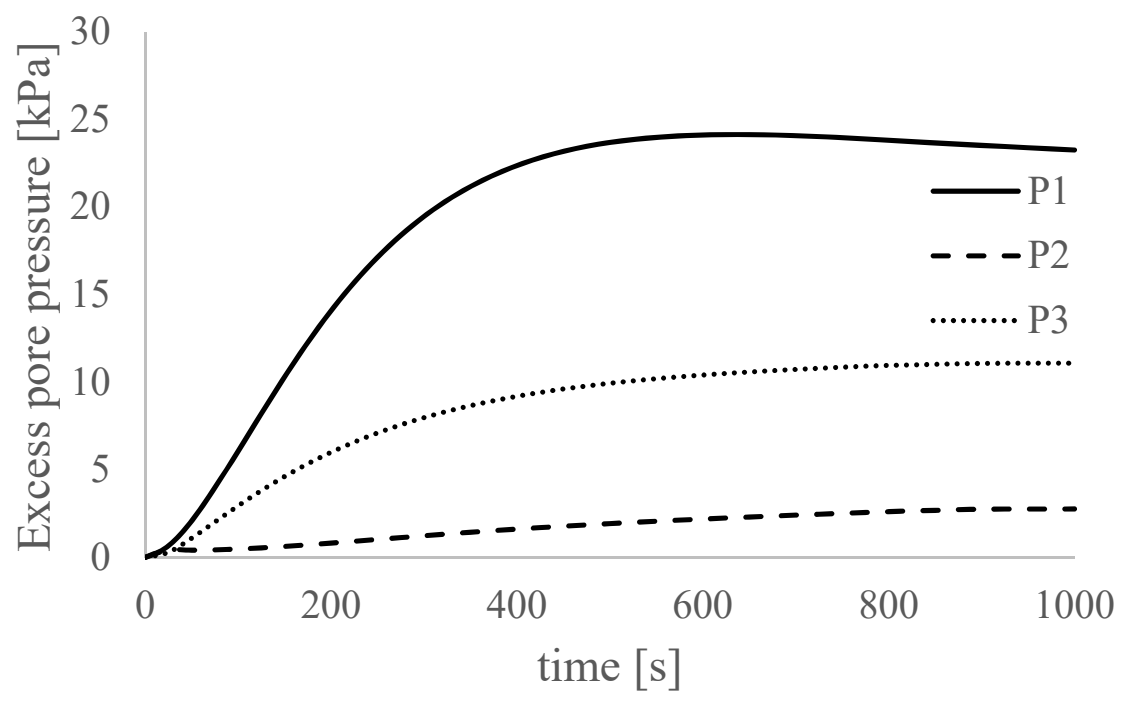

831 Figure 12. Excess pore water pressure at three points located in the sliding surface. (a) Case 1. (b) Case 2. 


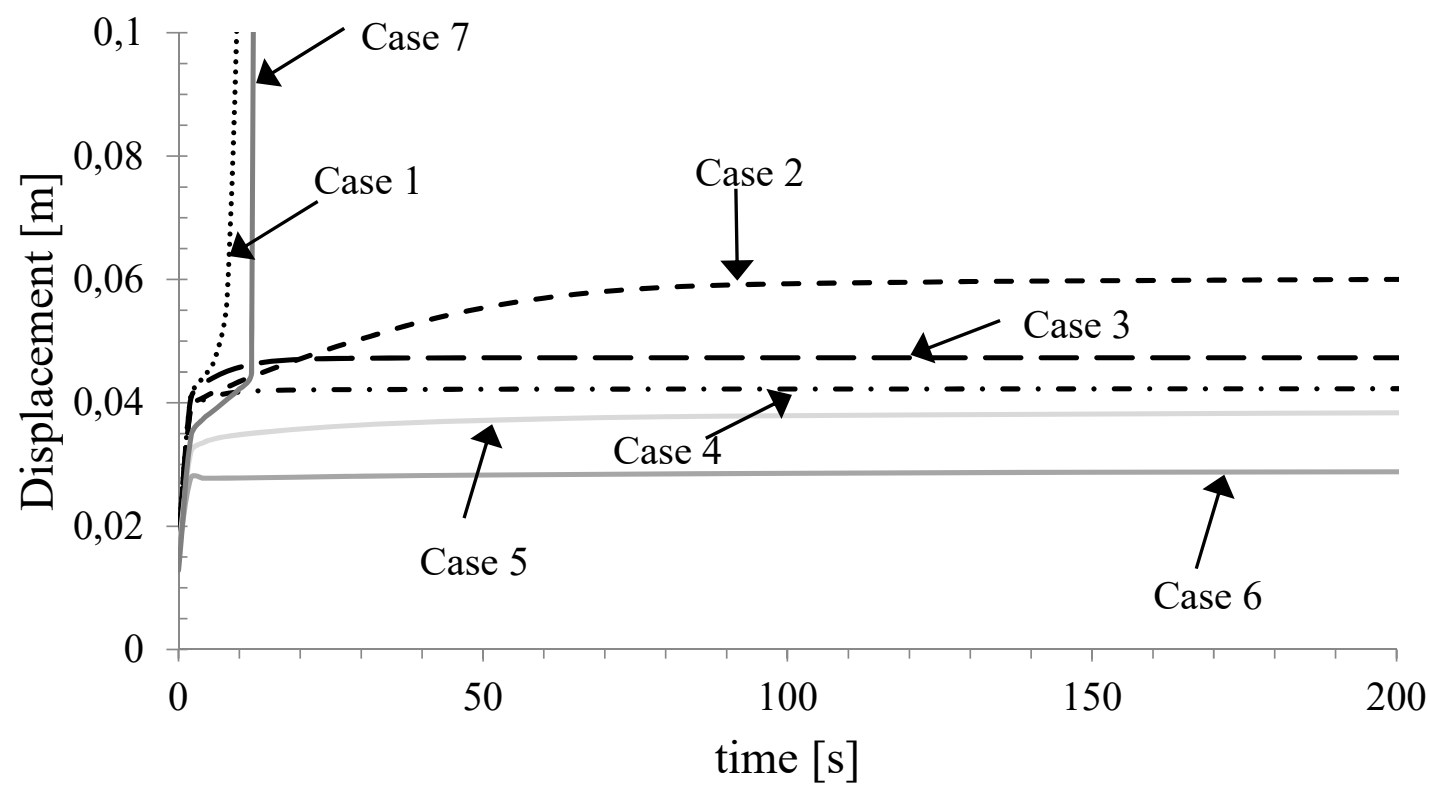

Figure 13. Displacement evolution for a point in the landslide toe for all cases described.

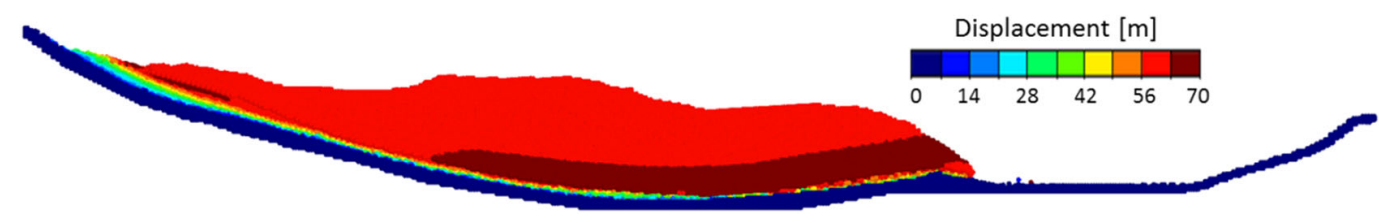

(a)

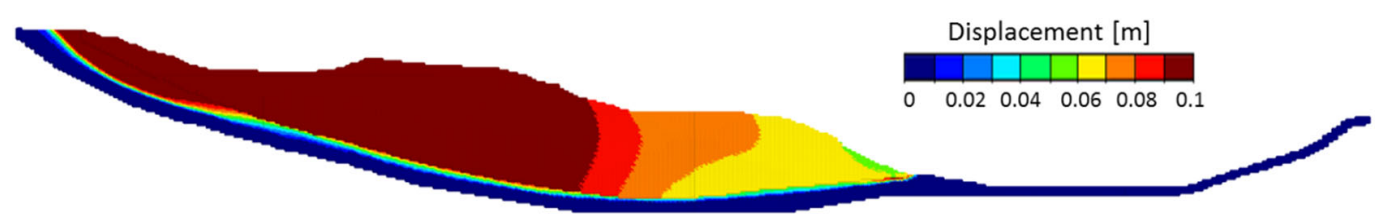

(b)

839

Figure 14. Accumulated displacement and deformed geometry at the end of the motion. (a) Case 1, (b) Case 841 2

842 


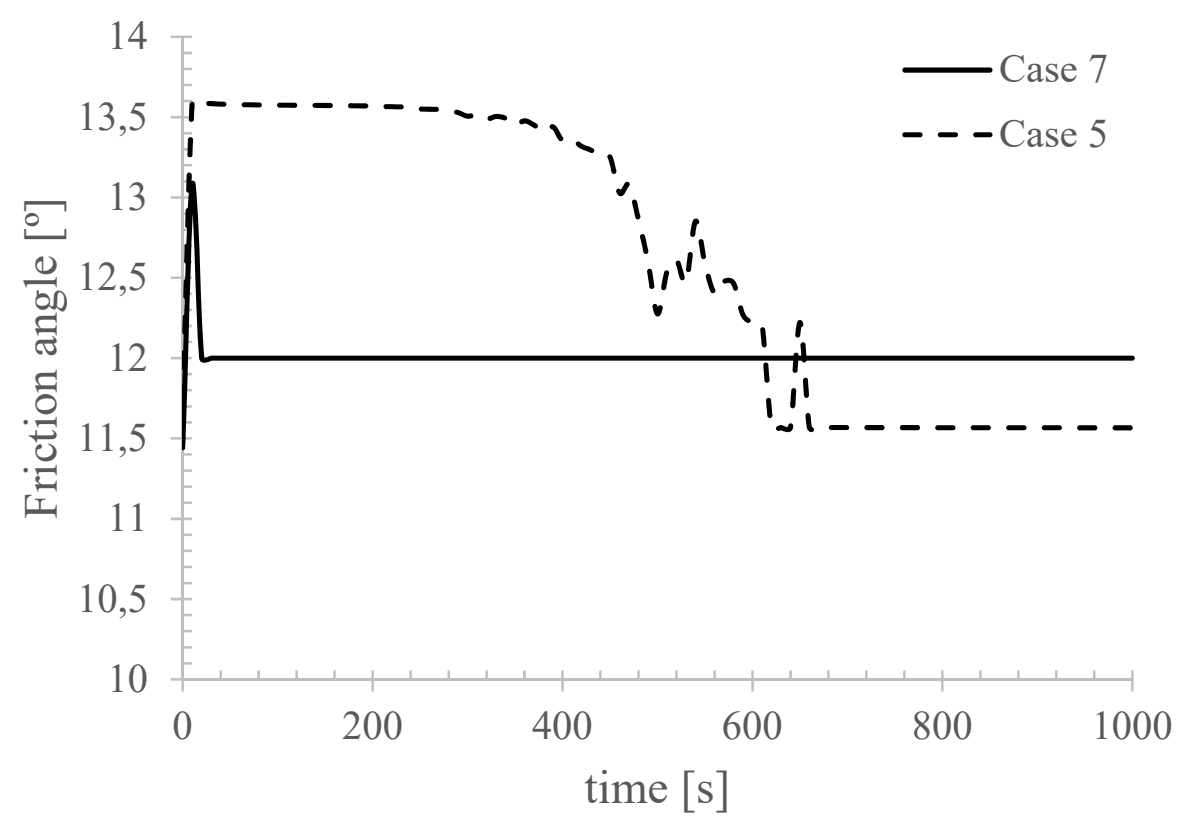

844

845 Figure 15. Friction angle evolution for Case 5 and 7 thermal interactions, strain rate effects and a peak to 846 residual strength reduction

847 